ANL-85-38

$\frac{30}{7 / 16 / 85} w B$ B 1 Cat 38

$$
\begin{aligned}
& 27.113^{3-9} \\
& I-21856
\end{aligned}
$$

\title{
EXPERIMENTAL STUDY ON IMPACTIFRETTING WEAR IN HEAT EXCHANGER TUBES
}

\author{
by \\ J. H. Cha, M. W. Wambsganss, \\ and J. A. Jendrzejczyk
}

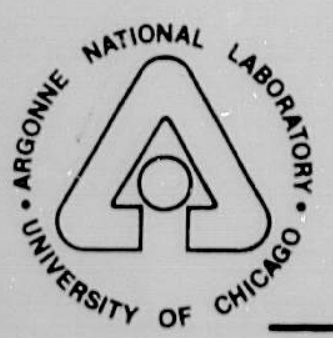

ARGONNE NATIONAL LABORATORY, ARGONNE, ILLINOIS

Operated by THE UNIVERSITY OF CHICAGO

for the U. S. DEPARTMENT OF ENERGY

under Contract Wy-31-109-Eng-38 


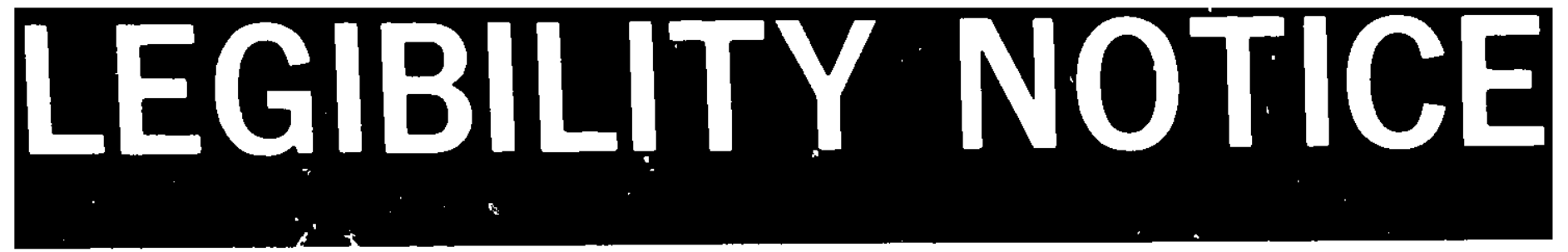

A major purpose of the Technical Information Center is to provide the broadest dissemination possible of information contained in DOE's Research and Development Reports to business, industry, the academic community, and federal, state and local governments.

\section{Although a small portion of this} report is not reproducible, it is being made available to expedite the availability of information on the research discussed herein. 


$$
\begin{aligned}
& \text { ANL- }-85-38 \\
& \text { DE85 } 014597
\end{aligned}
$$

ARGONNE NATIONAL LABORATORY

9700 South Cass Avenue

Argonne, Illinois 60439

EXPERIMENTAL STUDY ON IMPAC 2 /FRETTING WEAR IN HEAT EXCHANGER TUBES

by

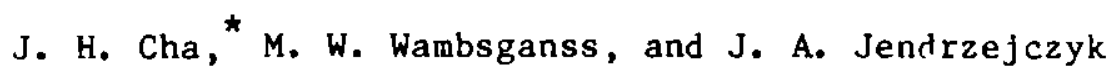

Components Technology Division

April 1985

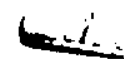

${ }^{\star}$ Visiting Scientist, Korea Advanced Energy Research Institute 
CONTENTS

Page

ABSTRACT. ..................................... 7

I. InTRODUCTION. ................................ 8

II. TEST DESCRIPTION..............................

A. Test Hardware...............................

B. Test Procedure............................... 19

C. Test Parameters and Conditions.................... 21

III. TEST RESULTS................................. 22

A. Tube Motion................................. 22

B. Impact Force.............................. 24

C. Clearance between Tube and Tube Support Plate.......... 24

D. Tube Support Plate Th1ckness...................... 30

E. Excitation Frequency......................... 30

F. Duration of Test........................... 36

G. Material Combination........................ 36

H. Liquid Environment.......................... 42

IV. Discussion. $\ldots \ldots \ldots \ldots \ldots \ldots \ldots \ldots \ldots \ldots \ldots \ldots \ldots \ldots \ldots \ldots \ldots \ldots \ldots \ldots \ldots$

v. CONCLUSIONS.................................. 50

ACKNOWLEDGMENTS................................... 52

REFERENCES....................................... 53 


\section{FIGURES}

Page

General Photographic View of Test Apparatus............... 10

Photograph of Tube, Excitation Coils and Test Section.........

12

3 Schematic of Test F1xture............................ 13

4 Close-up Photograph of Wear Test Section................ 14

5 Photograph1c View of Force Transducer Mount1ng Block......... 15

6 Sectlonal View of Force Transducer Mounting Block.......... 16

$7 \quad$ General Dfagram of Test Apparatus................... 17

8 Photograpnic View of In-Water Test................... 18

9 Photograph of Specimen Samples....................... 20

10 Examples of Tube Vibration Patterns.................... 23

11 Sample of Force and Displacement Records without Preload...... 25

12 Sample of Force and Displacement Records with Preload........ 26

13 Impact Force vs. Excitation Force at Tube Support Plate...... 27

14 Wear Rate vs. Impact Force, Frequency: $26 \mathrm{~Hz}$, Tube/TSP

Clearance (diametral): $0.78 \mathrm{~mm}$, TSP Thickness: $14.27 \mathrm{~mm}$,

Preload: None...................................

15 Wear Rate vs. Tube/TSP Clearance, Excitation Force: $6.14 \mathrm{~N}$, Frequency: $26 \mathrm{~Hz}$, TSP Thickness: $14.27 \mathrm{~mm}$, Preload: $5.56 \mathrm{~N} . \ldots$

16 Impact Force vs. Tube/TSP Clearance without Preload, Frequency: $26 \mathrm{~Hz}$, TSP Thickness: $14.27 \mathrm{~mm} . \ldots \ldots \ldots \ldots \ldots \ldots \ldots \ldots \ldots \ldots$

17 Impact Force vs. Tube/TSP Clearance with Preload, Frequency:

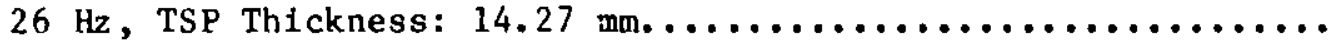

18 Wear Rate vs. TSP Thickness, Excitation Force: $6.14 \mathrm{~N}$, Frequency: $26 \mathrm{~Hz}$, Tube/TSP Clearance (dlametral): $0.78 \mathrm{~mm}$,

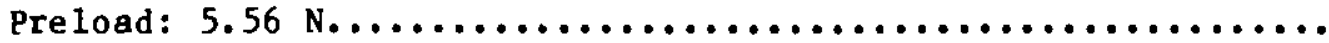

19 Wear Rate Variation with Frequency. Impact Force: $39 \mathrm{~N}$, Tube/ TSP Clearance (dlametral): $0.78 \mathrm{~mm}$, Materlal: Carbon Stee1,

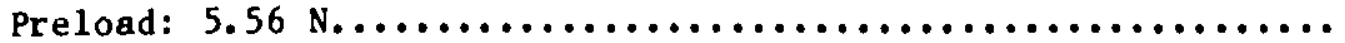


21 Wear Rate as a Function of Test Duration, Excitation Force:

$6.14 \mathrm{~N}$, Frequency: $26 \mathrm{~Hz}$, Tube/TSP Clearance (diametral):

$0.78 \mathrm{~mm}$, TSP Thickness: $14.27 \mathrm{~mm}$, Preload: None............

22 Wear Rate as a Function of Test Duration, Excltation Force:

$6.14 \mathrm{~N}$, Frequency, $26 \mathrm{~Hz}$, Tube/TSP Clearance (dfametra1):

$0.78 \mathrm{~mm}$, TSP Th1ckness: 14.27, Preload: $5.56 \mathrm{~N} . \ldots \ldots \ldots \ldots . . . .38$

23 Wear Rate with Test Duration for Carbon Steel/304 Stainless

Steel Combination, Excitation Force: $6.14 \mathrm{~N}$, Frequency: $26 \mathrm{~Hz}$, Tube/TSP Clearance (diametral): $0.78 \mathrm{~mm}$, TSP Thlckness:

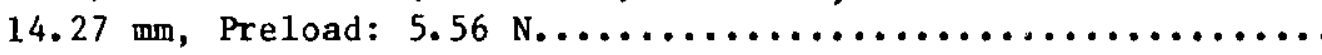

24 Wear Rate with Test Duration for Carbon Steel/Inconel 600

Combination, Excitation Force: $6.14 \mathrm{~N}$, Frequency: $26 \mathrm{~Hz}$,

Tube/TSP Clearance (ilametral): $0.78 \mathrm{~mm}$, TSP Thickness:

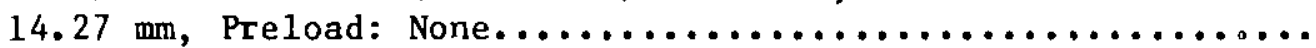

25 Wear Rate with Test Duration for Carbon Steel/Brass

Combination, Excitation Force: $6.14 \mathrm{~N}$, Frequency: $26 \mathrm{~Hz}$,

Tube/TSP Clearance (diametral): $0.78 \mathrm{~mm}$, TSP Thickness:

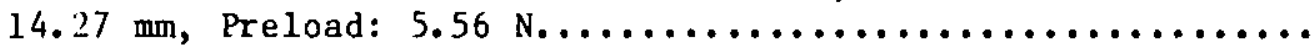

26 Comparison of Wear Rates of In-Alr and In-Water Tests,

Excitation Force: $6.14 \mathrm{~N}$, Frequency: $26 \mathrm{~Hz}$, Tube/TSP Clearance

(d1ametral): $0.78 \mathrm{~mm}$, TSP Thickness: $14.27 \mathrm{~mm}$, Material:

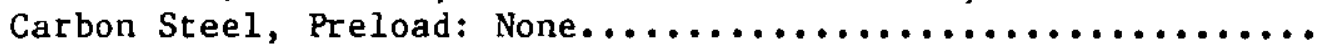

27 Comparison of Wear Rates of In-Air and In-Water Tests,

Excitation Force: $6.14 \mathrm{~N}$, Frequency: $26 \mathrm{~Hz}$, Tube/TSP Clearance

(diametra1): $0.78 \mathrm{~mm}$, TSP Thickness: $14.27 \mathrm{~mm}$, Material:

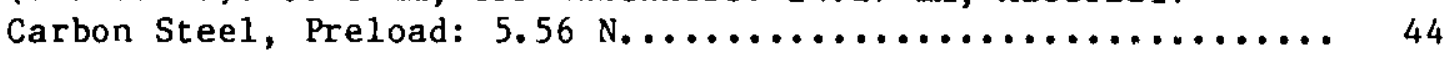

28 Appearance of a worn Tube Specimen................... 46

29 Microphotograph of a Worn Surface of 304 Stalnless Steel Tube

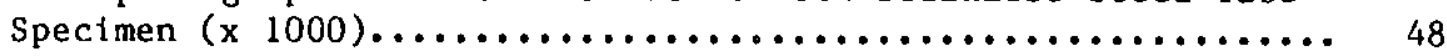

30 Microphotograph of a Worn Surface of Inconel 600 Tube

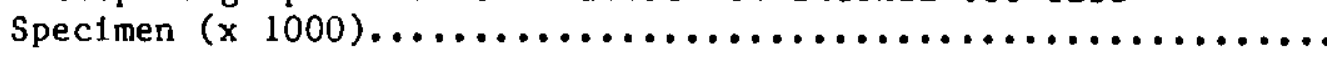

31 Comparison of Experimental Data and Empirical Curvefit of

Eq. (1) for Carbon Steel/Carbon Steel Combination In Air...... 
TABLES

$\underline{\text { Page }}$

$1 \quad$ Material Specifications........................... 19

2 Selected Parameters and Test Conditions................. 21 
EXPERIMENTAL STUDY ON IMPACT ; FRETTING WEAR IN HEAT EXCHANGER TUBES

by

J. H. Cha, M. W. Wambsganss, and J. A. Jendrzejczyk

ABSTRACT

A data bank of fleld experiences with heat exchanger tube vibration reveals numerous cases of tube failures at, or near, the baffle. The fallures can be attributed to 1mpact and/or fretting wear due to flow-1nduced vibrations. In spite of the nccurrence of serious wear problems in heat exchangers, only a few Investigations have been reported. The objective of this study is to provide qualitative impact/fretting wear information for heat exchanger tubes through the performance of a series of tests involving the pertinent parameters: 1mpact force level, between the tube and its support; tube to support plate hole clearance; tube support plate thickness; and tube vibration frequency. The characteristics of 1mpact/fretting wear relative to tube motion pattern, material combination and surrounding fluid were also investigated. The test apparatus consists of a cantilevered tube with a simulated tube support plate at the "free end". Tube vibration is induced by an electromagnetic exciter to simulate the flow-induced tube motion occurring in a real heat exchanger at the tube/tube support plate interface. Tests are conducted in air, water, and oil, all at room temperature. Removable wear rings are attached to the tube free end and simulated support fixture. Wear ring materials include carbon steel, 304 stalnless steel, Inconel 600 and brass. The resulting 1mpact/fretting wear $1 \mathrm{~s}$ measured by the weight $10 \mathrm{~s}$ technique. The principal results of the tests are as follows: Wear rate increases significantly with the magnitude of the Impact force between the tube and its support plate; the degree and trend of the wear rates are highly dependent on the mechanical and metallurgical properties of the tube/support material combination; the rate of impact/fretting wear decreases with increasing frequency. The results also show that the wear rate for carbon steel in water is greater in comparison with the values from the in-air tests. On the other hand, the wear rate from tests in ofl is very much lower than the results from the tests in both air and water. An empirical formula is proposed to correlate the experimental impact/fretting wear results. 


\section{INTRODUCTION}

Because of the small clearance existing between a heat exchanger tube and the tube support plate hole, flow-1nduced vibration of the heat exchanger tube bundle can cause relative motion at the tube/support Interfaces which, in turn, can result in 1mpact/fretting wear. Severe impact/fretting wear w1ll eventually lead to heat exchanger tube fallures as documented in a series of heat exchanger tube vibration data bank reports published by Argonne National Laboratory [1]. The case histories of field experfences include numerous examples of tube cutting fallures at, or near, the baffles which can be attributed to impact/fretting wear due to flowinduced vibration.

There is a large volume of 11terature on the subject of wear that includes presentations of wear data, discusstons of wear testing techniques, and the development of mathematical models for wear. However, in spite of the seriousness of impact/fretting wear problems in heat exchangers, there is only 1imited information reported in the open literature on tube/support wear in heat exchingers, or steam generators.

Numerous data were obtalned in the early stages of the investigation of the fretting wear mechanism as an aspect of tribological science. For example, Feng and Uh11g [2] observed and reported several charateristics of fretting wear with mild steel. These included the following: Metal loss increases with load and relative slip; greater damage occurs at temperatures below room temperature; damage is greater in dry alr than in moist alr: fretting wear is reduced in a vacuum or an inert atmosphere.

Significant Investigations which have contributed to the understanding of tube/support wear in heat exchangers have been made by Ko [3] and Blevins $[4]$.

In Ko's tube wear tests, a single span cantilevered tube, with tube and tube support plate specimens located at the free end, is used. A speclaily designed vibration generator allows for controlled umsirectional, or combined impact and sliding, motions. Fretting wear rate is measured for various material combinations and geometries. Ko's major results show that the fretting wear rate increases with tube support reaction forces and tube/support clearances; and that the wear rate is higher under combined impact and rubbing motions compared with impact motion alone.

Blevins made measurements of fretting wear using a test rig in which a tube, attached at its midpoint to a shaker, is vibrated such that 1mpacting and rubbing can occur between the tube and simulated support plates located at each of the free ends. Blevins measured wear as a function of such parameters as midspan vibration amplitude, vibration frequency, preload agalnst support, tube/support clearance, support plate thickness, tube wall th1ckness, and tube and support plate materials. Some interesting results of his tests are as follow: The wear rate of the tube and support plate are approximately equal if both the tube and the support plate are made of the same material; the wear rate is a function of the material and 1 ts hardness: 
the fretting wear rate increases with both the frequency and amplitude of tube vibrations; the wear rate decreases sharply with increasing preload applied to the tube at the tube/support interface. Blevins has also presented an investigation [5] on the development of a vibration-induced wear model based on inpact theory and the measurement of wear rates in helium at high temperature, up to $650^{\circ} \mathrm{C}$.

In order to analyze the impact/fretting wear process, fundamental studies of tube/support interaction forces and motions have been performed and reported by Chen et al. [6], Shin et al. [7], and Rogers and Pick $[8,9]$. In references 6 and 7 , only normal impacting is considered, whereas in references 8 and 9 two-dimenstonal, spatial motion is simulated. The results of the analytical simulations, when compared with experimental results from a single-span cantilevered tube [9] and a clamped-clamped tube with stop at midspan [7], have been shown to predict the basic trends and features of the interaction forces and motions as well as the amplitudes within 50 percent of the measured values. Axisa et al. [10] recently Investigated the relattonship between impact forces and non-linear tube motion based on an experimental study of the vibro-impact response of a straight segment of a U-bend steam generator tube with tube-baffle interaction at the support. Frick et al. [11] attempted to develop a procedure to produce vibration and wear time history information for steam generator and heat exchanger tubes using a single tube, 3-D, non-1inear dynamic model.

Previous investigacors have made significant contributions revealing the characteristics of fretting wear. Nevertheless, it is not yet clearly understood and much remains to be done. The objective of this study is to generate qualitative 1mpact/fretting wear data that will provide additional insights to this complex phenomenon that is so important in the design evaluation of heat exchangers. A series of tests are performed involving the essential parameters: Magnitude of fmpact force between tube and its suport; tube to support clearance; tube support plate thickness; and excitation frequency. Time-histories of tube 1mpact/fretting wear for several material combinations and the effect of surrounding fluid are also studied.

\section{A. Test Hardware}

\section{TEST DESCRIPTION}

The test apparatus consists of a cantilevered tube with a tube spectinen (wear ring) attached to the free end, a tube support plate (TSP) spectmen (wear ring) clamped in a steel and brass base block which 18 located at the level of the free end of the tube, an electromagnetic exciter assembly, a transducer assembly, the test apparatus frame, and related electronic equipinent. A general view of the test aparatus is shown in Fig. 1.

The tube, $16 \mathrm{~mm}$ OD $\times 1.2 \mathrm{~mm}$ thickness $\times 953 \mathrm{~mm}$ long and fabricated of seainless Croloy $(2-1 / 4 \%$ Cr $-1 \%$ Mo $)$, is vertically mounted and securely 


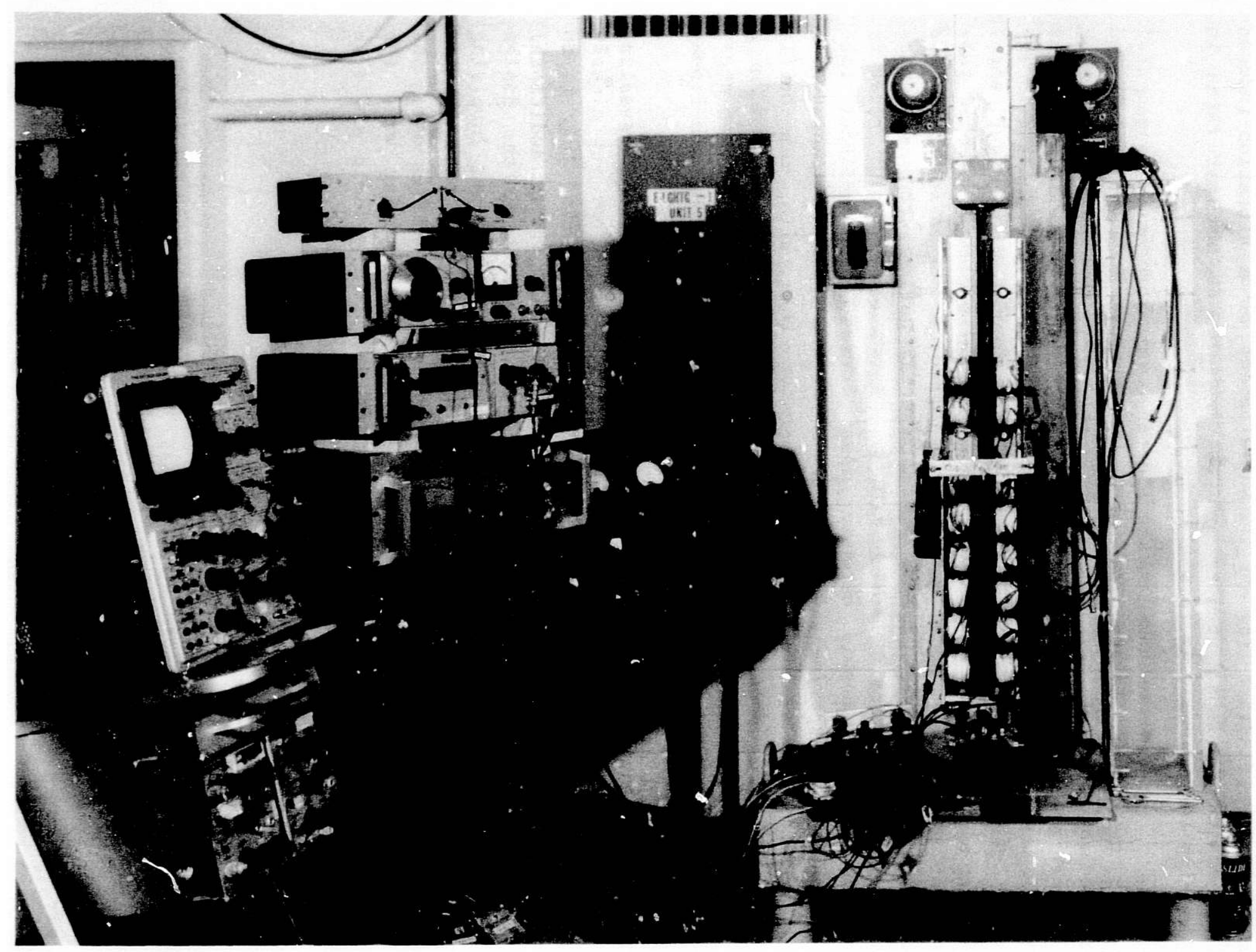

Fig. 1. General Photographic View of Test Apparatus (ANL Neg. No. 113-85-16) 
clamped at its upper end to the frame. The tube is excited by an electromagnetic exiter assembly consisting of efght pairs of drive coils (300 turns of No. 12 Farmver wire for sach col1) mounted to the frame and posttioned along the length of the tube. The exclter assembly is connected to a sine-wave generator and power amplifier. The frequency of tube vibration is controlled by varying the stne-wave generator, and the excitation force level is controlled by the power amplifier. The tube and tube support plate specimens are in the form of annular wear rings. The excitation colls provide tube motion in the horizontal direction. The tube specimen is vibrated against a tube support plate specimen ard impact/fretting wear 18 produced between the two test specimens. A photograph of the cantilevered tube, excitation colls, and test section is shown in Fig. 2; a schematic representation is given in Fig. 3. In Fig. 4 is shown a close-up view of the support plate base block and the tube and tube support plate wear spectmens.

The test apparatus frame is composed of both vertical and horizontal members. The vertical member is a "strong-back" that provides support for the tube, excltation cofls, tube support plate specimen block and clamp, and the transducer assembly. The hortzontal member is a massive steel block which is laid on the laboratory floor and provides support for the vertical member. The test apparatus is made sufficiently rigld that significant interaction between tube and test fixture caused by mechanical coupling is avoided.

Tube vibration response, including frequency, amplitude, and tube/ support impact force is measured by displacement and force transducers. Two-dimensional transvarse displacement of the tube is sensed by a patr of Kaman Variable Impeaance Transducers (Model $\mathrm{KD}-2300-6 \mathrm{C}$ ) orthogonally orienter and mounted near the free end of the tube. Impact force between the tube and tube support plate specimens is measured with a triaxial piezoelectric force transducer (Kistler Model 9067) inserted between the tube support plate specimen block and transducer mounting block as seen in Figs. 5 and 6. A separate force transducer block was fabricated to be similar in function and geometry to that of the maln wear test block. The force transaucer block was installed by replacement of the main block whenever impact force measurements were desired.

An oscilloscope was used to visually observe the tube motions sensed by the displacement transducers. The displacements and forces were analyzed with a Fast Fourter Analyzer (Mode1 H.P. 5451C), and force time histories, power density spectra, and force histograms were produced. A schematic of the instrumentation and associated electronics is shown in the diagram of Fig. 7 .

For the in-water and in-oil tests, a acrylic plastic $(200 \times 200 \times$ $150 \mathrm{~mm}$ ), which was sealed by rubber strips at the flanges, surrounds the test specimens and allows for immersing the test specimens in efther water or oil, as shown in Fig. 8 . 


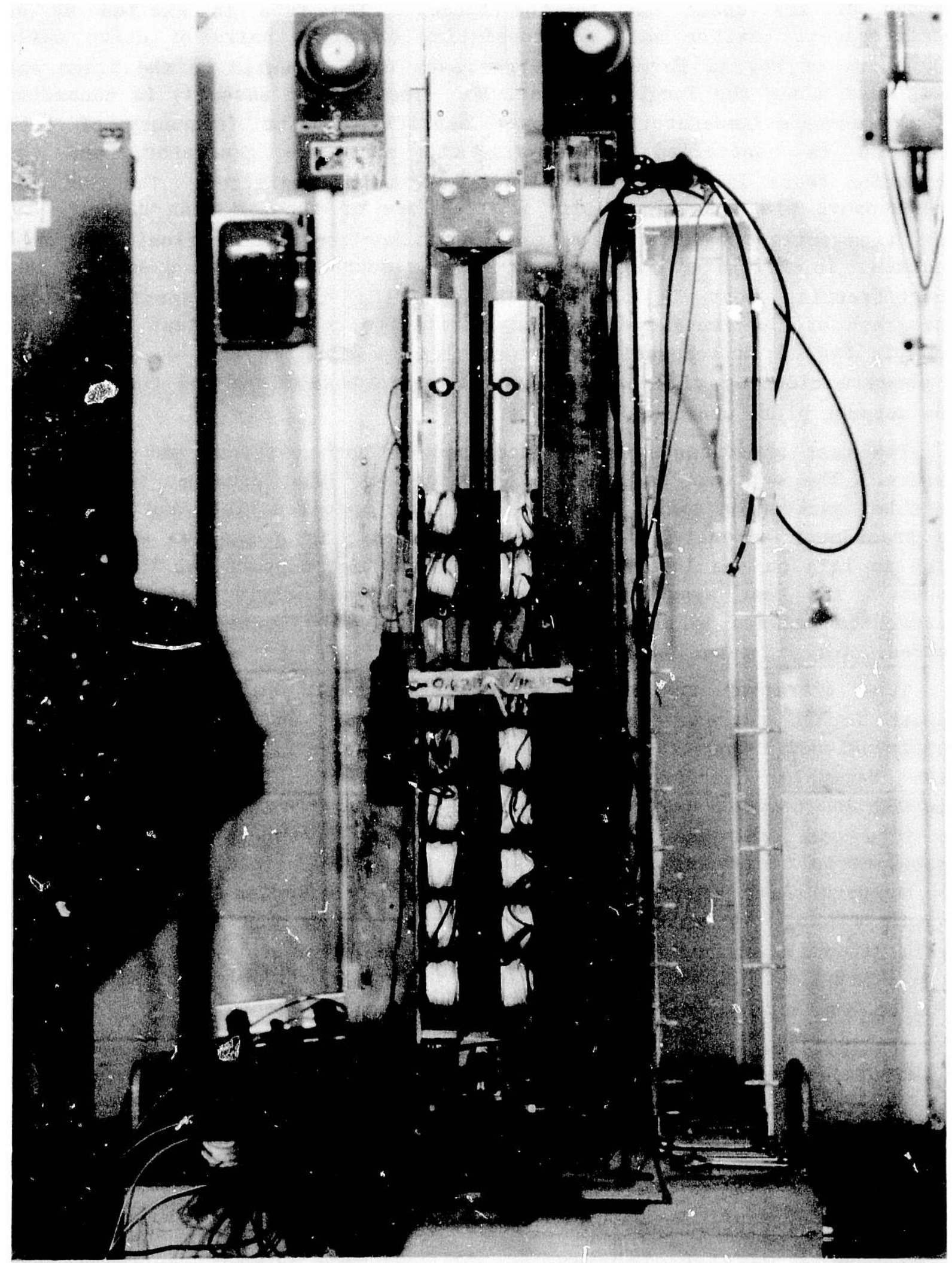

Fig. 2. Photograph of Tube, Excitation Coils and Test Section (ANL Neg. No. 113-85-15) 


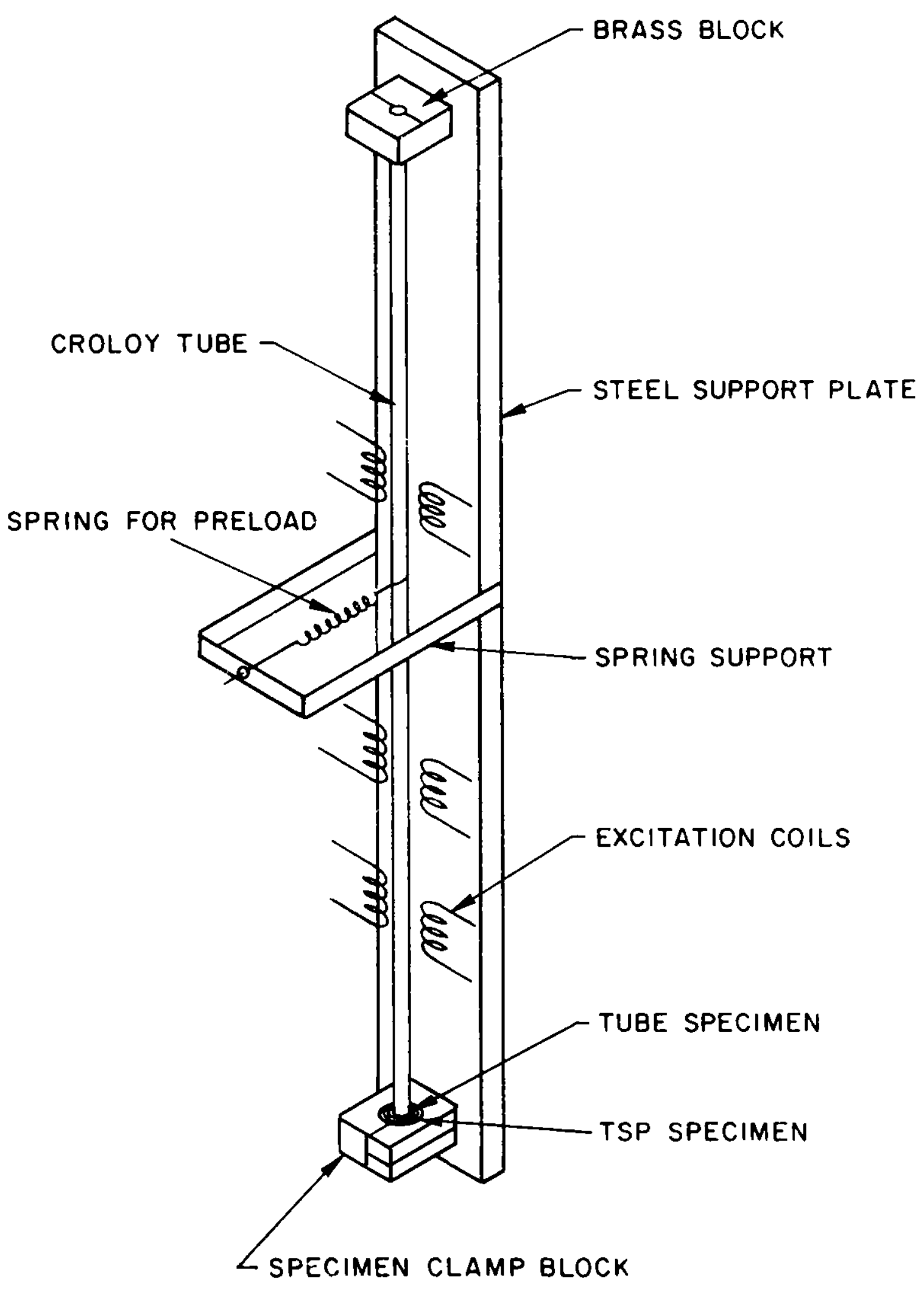

F1g. 3. Schematic of Test Fixture 


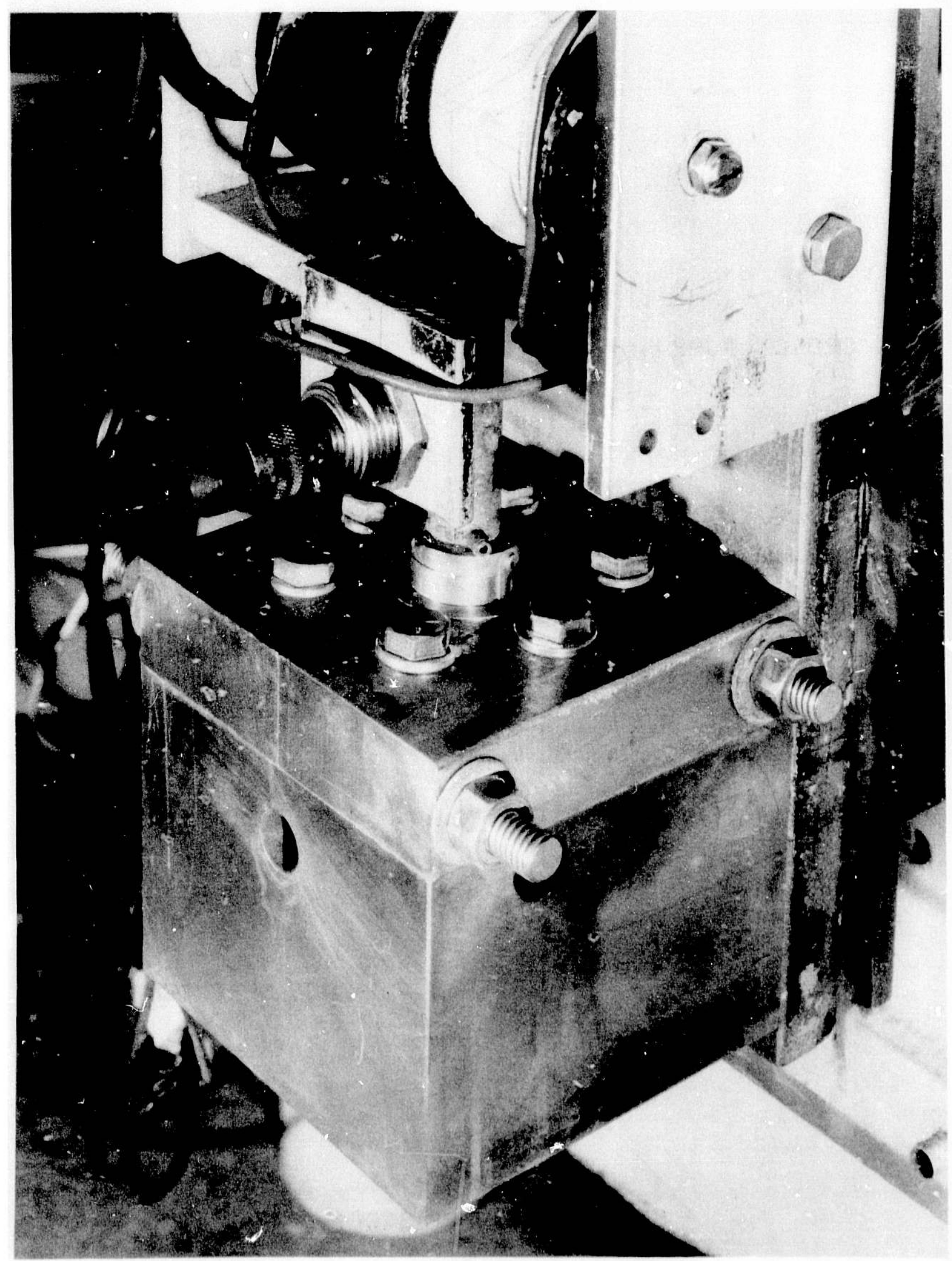

F1g. 4. Close-up Photograph of Wear Test Section (ANL Neg. No. 113-85-5) 


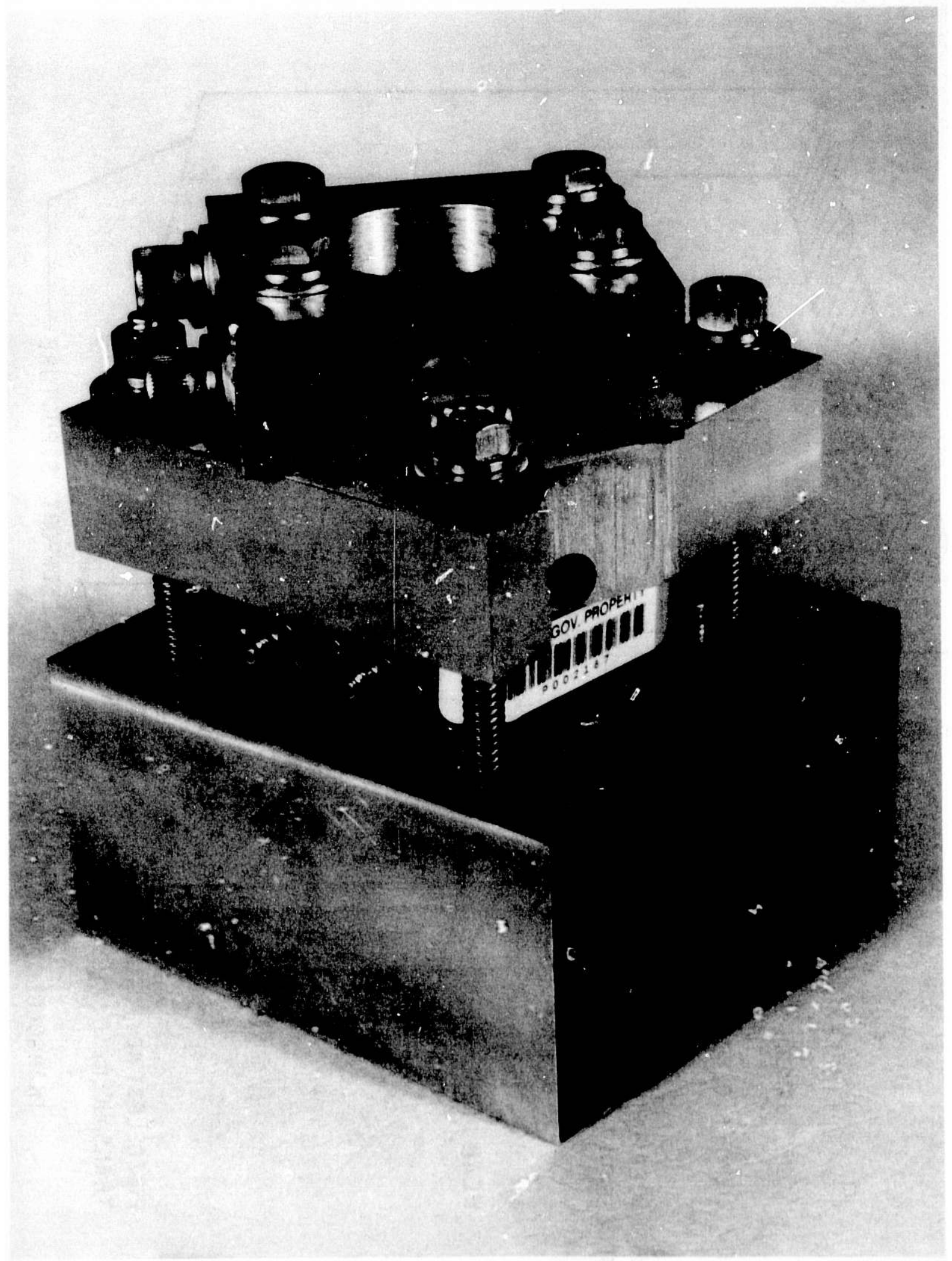

Fig. 5. Photographlc View of Force Transducer Mounting Block (ANL Neg. No. 113-85-8) 


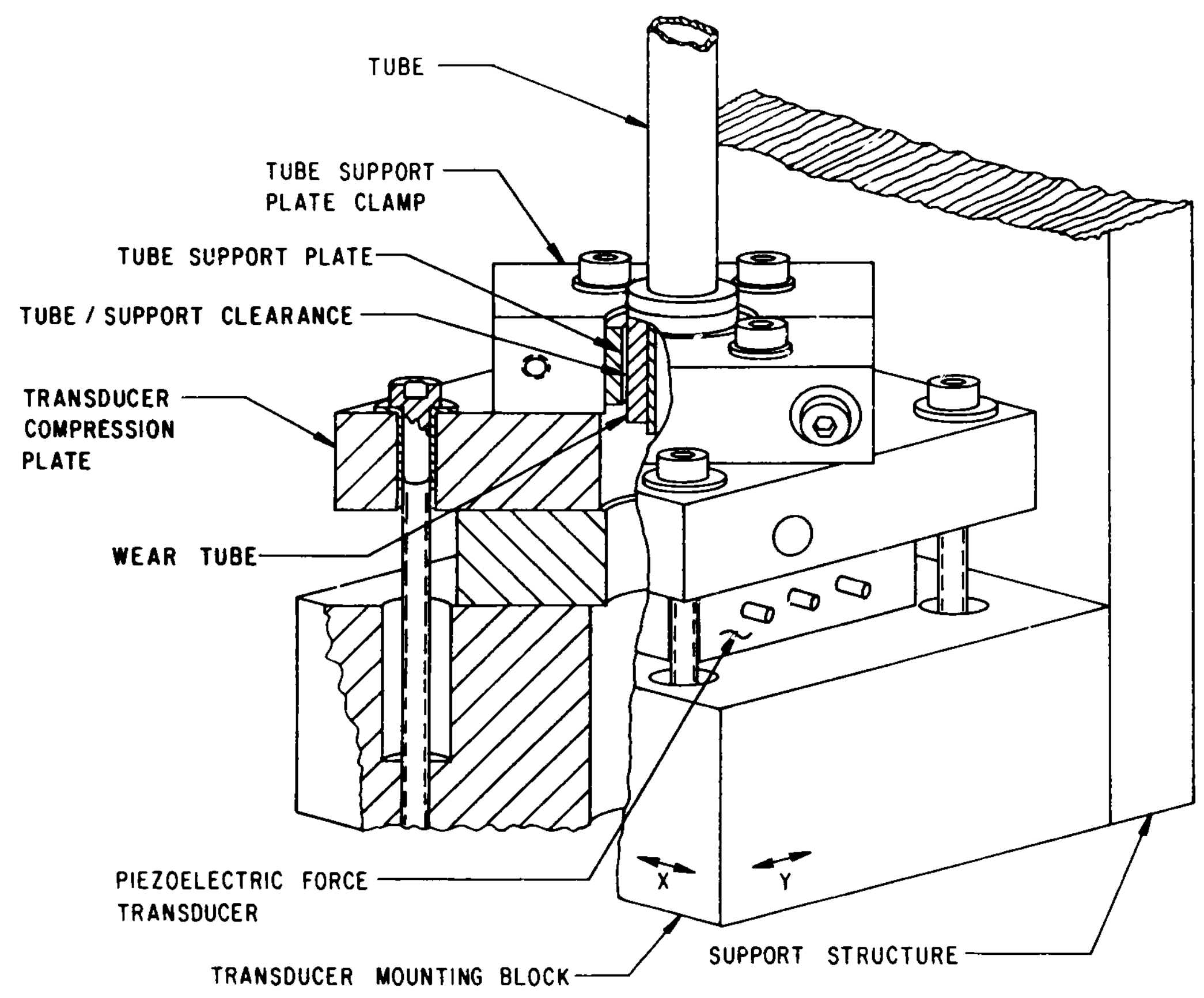

Fig. 6. Sectional View of Force Transducer Mounting Block 


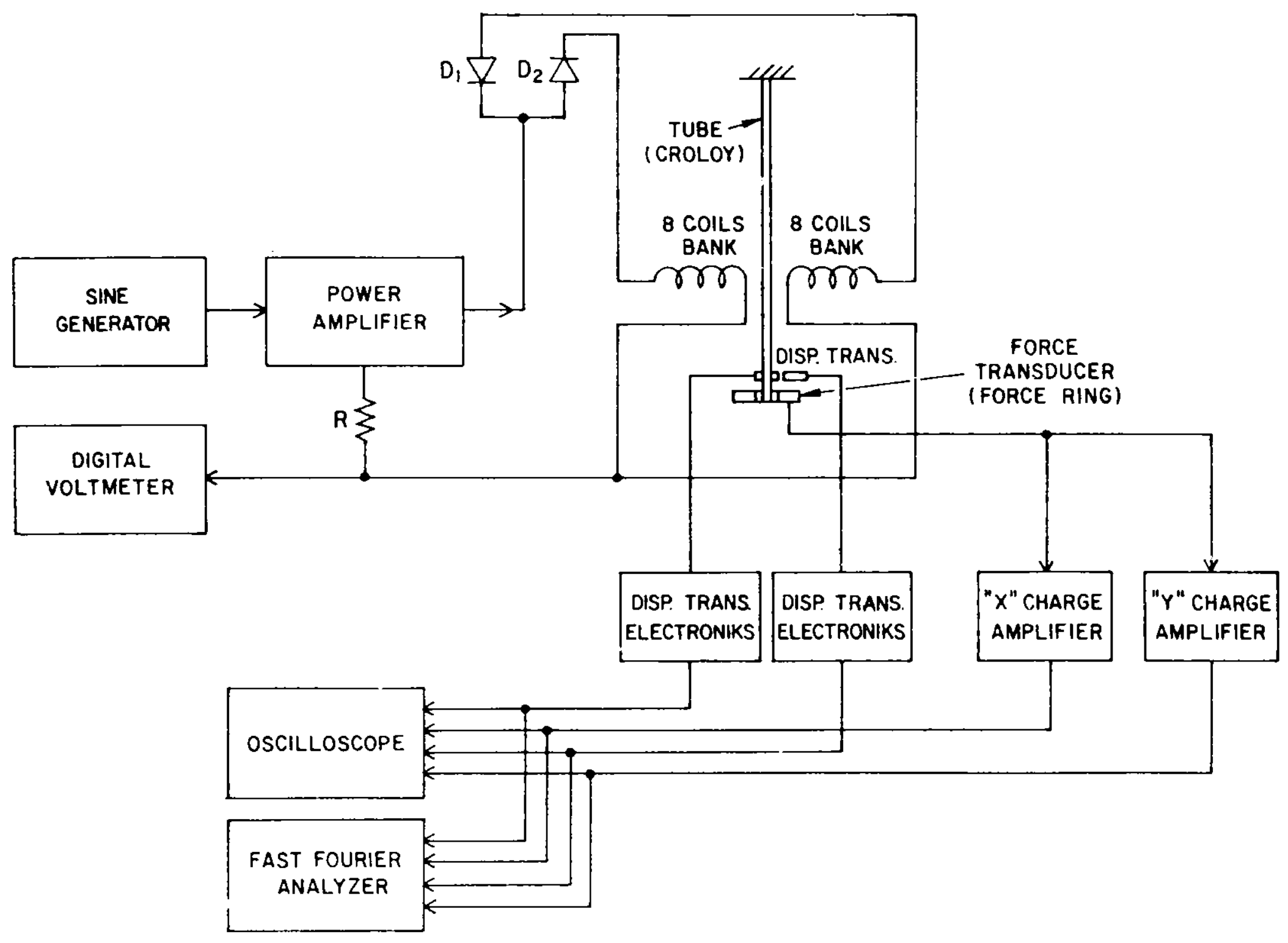

Fig. 7. General Diagram of Test Apparatus 


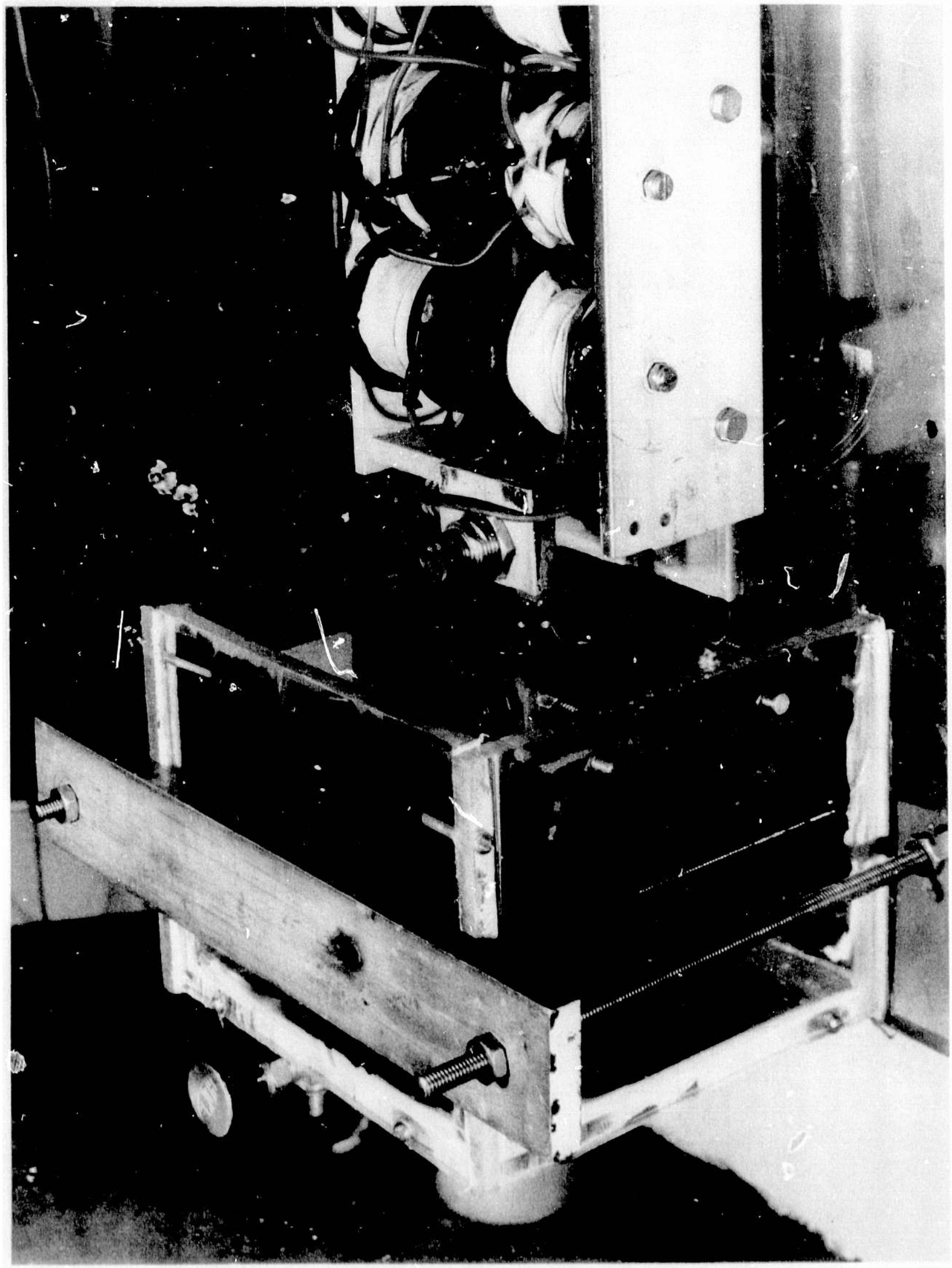

Fig. 8. Photographic View of In-Water Test (ANL Neg. No. 113-85-6) 
Carbon steel, 304 stainless steel, Inconel 600 and brass wer a chosen as the test specimen materials. Carbon steel, 304 stainless steel, and brass are commonly used for Industrial, process plant shell-and-tube type heat exchanger applications, while Inconel 600 is used in nuclear steam supply systems. The speciflc gravity, hardness, and chemical composition of those materials are listed In Table 1.

Table 1. Material Speciftcations

\begin{tabular}{|c|c|c|c|}
\hline Name of Material & $\begin{array}{l}\text { Spectfic } \\
\text { Gravity }\end{array}$ & $\begin{array}{l}\text { Hardness } \\
\text { (Rockwe11) }\end{array}$ & $\begin{array}{c}\text { Chemical Composition } \\
(\text { wt } \%)\end{array}$ \\
\hline Carbon Steel & 7.84 & B84 & $\begin{array}{l}\mathrm{C}: 0.45, \mathrm{S1}: 0.67, \mathrm{Mn}: \mathrm{l} .1 \\
\text { and } \mathrm{Al}, \mathrm{Co} \text {, Rest: }\end{array}$ \\
\hline 304 Stainless Steel & 8.04 & B86 & $\begin{array}{l}\mathrm{N} 1: 8-10.5, \mathrm{Cr}: 18-20, \mathrm{C}: 0.08, \\
\mathrm{Mn}: 2.00, \mathrm{~S} 1: 1.00 \text {, Rest: Fe }\end{array}$ \\
\hline Inconel 600 & 8.43 & B87 & $\begin{array}{l}\text { N1: } 76, \mathrm{Cr}: 15.5, \mathrm{Fe}: 8, \\
\mathrm{Mn}: 0.25, \mathrm{Cu}: 0.25 \text { and } \mathrm{Si}, \mathrm{C}, \mathrm{S}\end{array}$ \\
\hline Brass, Alpha & 8.49 & B8 2 & $\mathrm{Cu}: 65, \mathrm{Zn}: 35$ \\
\hline
\end{tabular}

Four tube/support hole diameiral clearances $(0.20,0.38,0.78$ and $1.58 \mathrm{~mm})$ and three tube support plate thicknesses $(9.52,14.27$ and $19.05 \mathrm{~mm}$ ) were selected as test parameters based, in part, on recommendations given in the TEMA Standards [12]. The tube wear specimens are nominally $25.4 \mathrm{~mm}$ length with a $16 \mathrm{~mm} \mathrm{ID,} \mathrm{and} \mathrm{outer} \mathrm{diameters} \mathrm{of} 25.197,25.019,24.613$ and $23.825 \mathrm{~mm}$, to allow for simulating the selected tube/support hole diametral clearances. The tube support plate wear specimens have a $25.4 \mathrm{~mm} 1 \mathrm{nner}$ diameter, a $35 \mathrm{~mm}$ outer diameter, and three different lengths as given above. Samples of the tube and tube support plate wear specimens are shown in Fig. 9.

\section{B. Test Procedure}

Following each fretting test run, the selected wear specimens were cleaned in an acetone bath with a soft brush in order to degrease them. They were then welghed three times on a precision analytical balance. The 


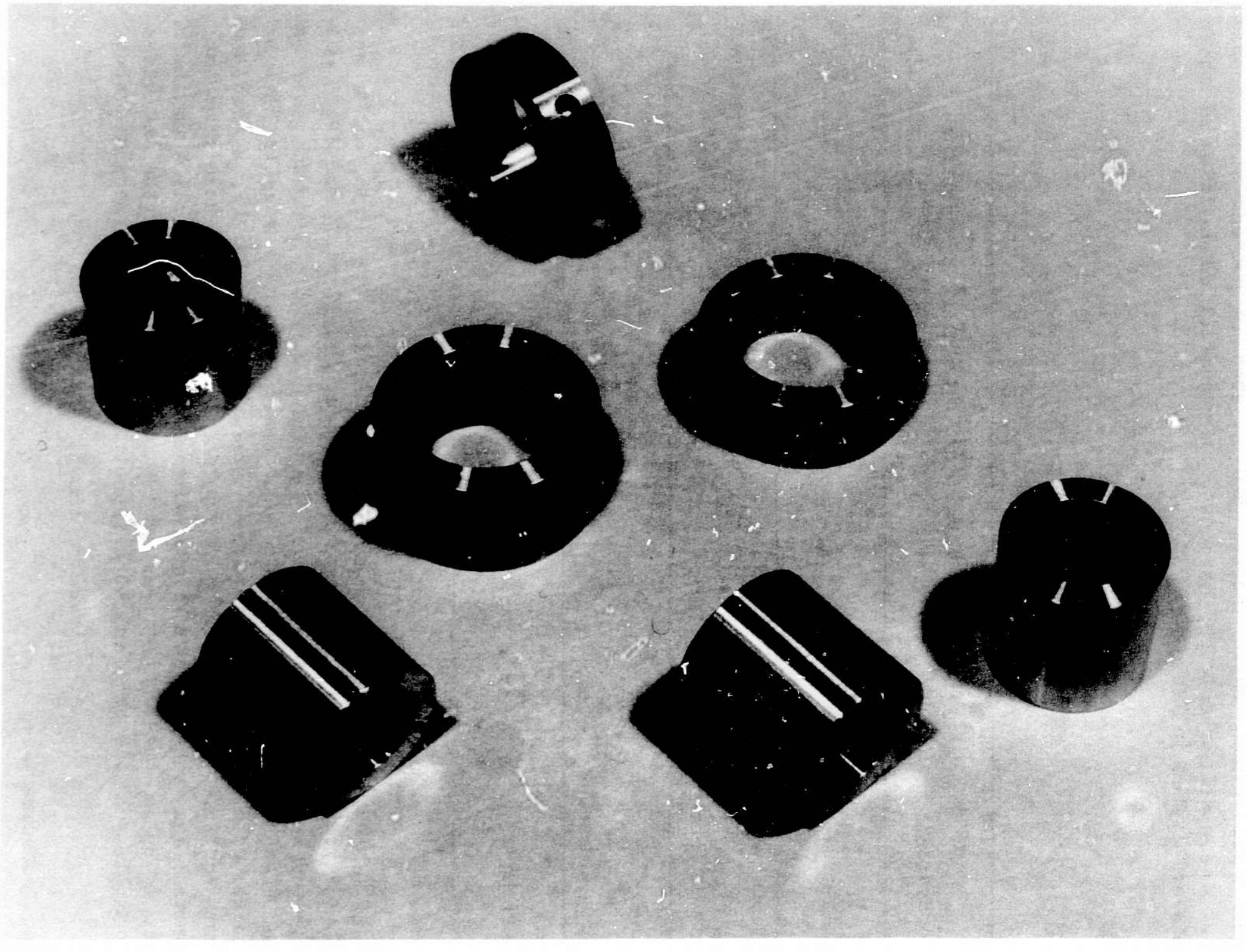

Fig. 9. Photograph of Specimen Samples (ANL Neg. No. 113-85-13) 
specimens were then Installed in the test rig and vibration inftiated at the desired excltation force level and frequency. Preload, if any, was applied to the midspan of the tube by spring tension as 1llustrated in Fig. 3 . Testing was terminated after continuous running for a giva: number of cycles. The wear specimens were recleaned, in order ta rinse off any loose debris, and reweighed. The weight loss of the specimens was calculated and normalized by dividing by the total number of cycles of vibration during the test run.

Upon completion of the in-air serfes of tests, the tank was attached and filled with room temperature water, and a similar set of tests was periormed. Following the 1n-water tests, the water was replaced by ofl and a set of 1n-oll tests was carried out. The ofl temperature was controlled by an immersion type heater equipped with a thermostat. The necessary signals from the transducers were tape recorded for further data processing.

C. Test Parameters and Conditions

Impact/fretting wear of heat exchanger tubes depends on the tube and support geometries, relative motion at the tube/support interface, the type and magnitude of tube/support reaction forces, material combinations, and environmental conditions. The following table lists the selected parameters and test conditions for this experimental study.

Table 2. Selected Parameters and Test Conditions

\begin{tabular}{|c|c|c|c|c|c|}
\hline $\begin{array}{c}\text { T/TSP } \\
\text { Clearance } \\
\text { (diametral, } \mathrm{mm} \text { ) } \\
\end{array}$ & $\begin{array}{c}\text { TSP } \\
\text { Thickness } \\
\text { (mm) }\end{array}$ & $\begin{array}{c}\text { Excitation } \\
\text { Force } \\
(\mathrm{N}) \\
\end{array}$ & $\begin{array}{l}\text { Excltation } \\
\text { Frequency } \\
(\mathrm{Hz}) \\
\end{array}$ & $\begin{array}{c}\text { Material } \\
\text { Combination } \\
\end{array}$ & Fluid \\
\hline 0.20 & 9.52 & 0.13 & 10 & CS:CS & Alr \\
\hline 0.38 & 14.27 & 0.28 & 26 & SS:SS & Water \\
\hline 0.78 & 19.05 & 0.54 & 40 & In: In & 011 \\
\hline \multirow[t]{4}{*}{1.58} & & 0.93 & 60 & $\mathrm{Br}: \mathrm{Br}$ & \\
\hline & & 1.38 & 80 & SS:CS & \\
\hline & & 1.87 & & In:CS & \\
\hline & & & & $\mathrm{Br}: \mathrm{CS}$ & \\
\hline
\end{tabular}

where CS: carbon steel, SS: 304 stainless steel, In: Inconel 600, Br: Brass 
In some tests a preload of $5.56 \mathrm{~N}$ was applied. The in-air and in-water tests were conducted at room temperature, the in-ofl tests were performed at a temperature of $45^{\circ} \mathrm{C}$. Most of the tests were run for 24 hours. However, some tests were run for 120 hours to observe the variation of wear rate with time.

\section{TEST RESULTS}

Experimental parameters known to influence 1mpact/fretting wear of heil exchanger tubes are generally contact conditions between the tube and 1 ts support, materfal properties and response behavior, and environmental conditions. The focus of this work is on those parameters for which results pertalning to 1mpact/fretting wear are tube mction, Impact force, clearance between tube and support plate hole, tube support plate thickness, frequency of vibration, test duration, material combination, and fluid environment.

A. Tube Motion

The flow-1nduced vibration mechanisms that can cause impact/fretting wear of heat exchanger tubes are fluidelastic excitation, turbulence buffeting, and vortex shedding. Fluidelastic excitation is belleved to be the cause of large amplitude vibration and, therefore, rapid wear of heat exchanger tubes. Wambsganss et al. [13] observed that, for the Industrial size shell-and-tube exchanger used in their tests, the primary contribution to the vibration. zesponse was in the frequency range from 10 to $80 \mathrm{~Hz}$; it was also observed that tube response associated with fluidelastic instability typically occurred in the frequency range of 20 to $30 \mathrm{~Hz}$. Based, in part, on these findings, the majority of the subject tests were performed at the low frequency of $26 \mathrm{~Hz}$.

Heat exchanger tubes are usually excited into different vibration patterns: random, stralght line in lift or drag direction, and whirling, depending, in part, on the flow range. A representative tube vibration pattern from tests of an actual heat exchanger is presented in Fig. 10(a) [14]. In the subject tests, the tube motions are determined by the excitation forces and the preload. Figures $10(b)$ and (c) are examples of typical tube vibration patterns that were employed. Figure 10(b) gives a vibration pattern corresponding to a low excitation force level $(0.28 \mathrm{~N})$ and Fig. 10(c) shows an example for a high excitation force level (1.38 N). The tests show that the ratio of the two orthogonal impact force components, $\mathrm{F}_{\mathrm{x}} / \mathrm{F}, \mathrm{y}$, is the range of 1.76 at lower excitation force and 4.50 at higher excitation force without preload, and 1.64 at lower excitation force and 1.92 at higher excitation force with preload. The ratio $F_{x} / F_{y}$ approximately equal to $\infty$ or 0 implies that the tube motion is primarily one of straight ine motion, giving rise to lmpacting. With $F_{x} / F_{y}$ approaching 1 the tube has the tendency to whirl. 


$$
100
$$




\section{B. Impact Force}

During the tests, Impact forces at the tube support plate were measured with a force transducer, together with the measurement of displacement variations. Figures 11 and 12 show sample t1me-historles of the variation of impact forces and displacements at the support location. It can be seen that $F_{y}$ and $D_{y}$ components in the preload case are somewhat larger than those for the case of no preload. The maximum values of two mutually perpendicular forces are used to represent the resultant impact force at the support. Figure 13 shows the relationship between the resultant 1mpact force at the support and the excitation force generated by the excitation cotls. The relationship is nearly itnear.

Figure 14 illustrates the influence of 1mpact force on the 1mpact/fretting wear rate of tubes for the case of a constant frequency excitation and tube/tube support plate in air. Each test point was taken after 24 hours running. The results show that the wear rate, for each of the four material comblnations, is rapidly increasing with increasing impact force level. It was learned from the results that the impact force at the support is the primary parameter determining wear. The wear rate as a function of impact force for the four materfals can be expressed as: $\mathrm{w}=\mathrm{k}_{1} \mathrm{~F}^{\mathrm{a}} 1$, where $\mathrm{w}$ is wear rate (mg/10 $\mathrm{cycles}$ ), $\mathrm{F}$ is resultant impact force $(N)$, and $k_{1}$ and $a_{1}$ are constants. Using least squares curve fitting techniques, the following constants were obtained: exponent $a_{1}$ is 1.72 for al1 four materials; and constant $k_{1}$ is 0.0068 for 304 stainless steel, 0.014 for carbon steel, 0.024 for Inconel 600 , and 0.12 for brass. The wear rate of 304 stainless steel is the lowest, while brass has the highest wear rate. There is no evidence of material hardness effect on wear when both the tube and the tube support plate are the same material.

In order to control the tube motion pattern, preload was applied on the tube, at a point $43.5 \mathrm{~cm}$ from the top of the tube, by means of the tension force of spring. It should be noted that while preload acts to increase the static force, it reduces the impact force and, in this case, results in reduced wear.

C. Clearance between Tube and Tube Support Plate

Data presented in Fig. 15 shows the effect of an increase in diametral clearance between the tube and tube support plate hole on the wear rate in air for the four materials with fixed excitation force level, excitation frequency, and tube support plate thlckness. In the tests, four clearances were examined by varying the outer diameter of the tube specimen; both the tube and tube support plate are made of the same material. The clearance in F1g. 15 refers to the clearances at the start of the tests. By the end of a 24 -hour test, these clearances had increased slightly. Figure 15 indicates the rapid increase in wear rate with increasing clearance between tube and support plate hole that many investigators have observed. The results allow one to conclude that the smaller the clearance between tube and tube support plate hole, the smaller will be the wear rate. The trend of Increasing wear 


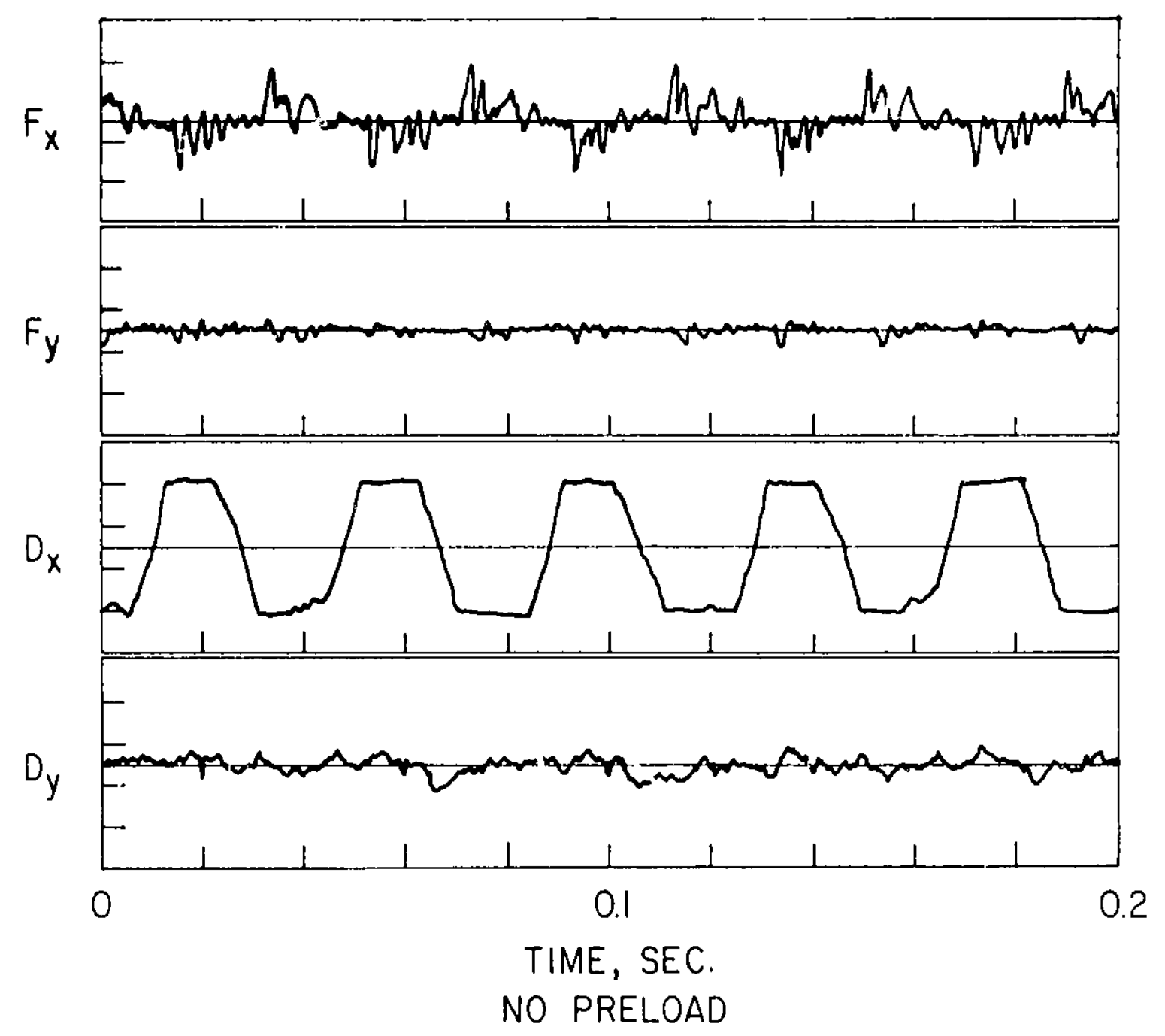

Fig. 11. Sample of Force and Displacement Records without Preload 


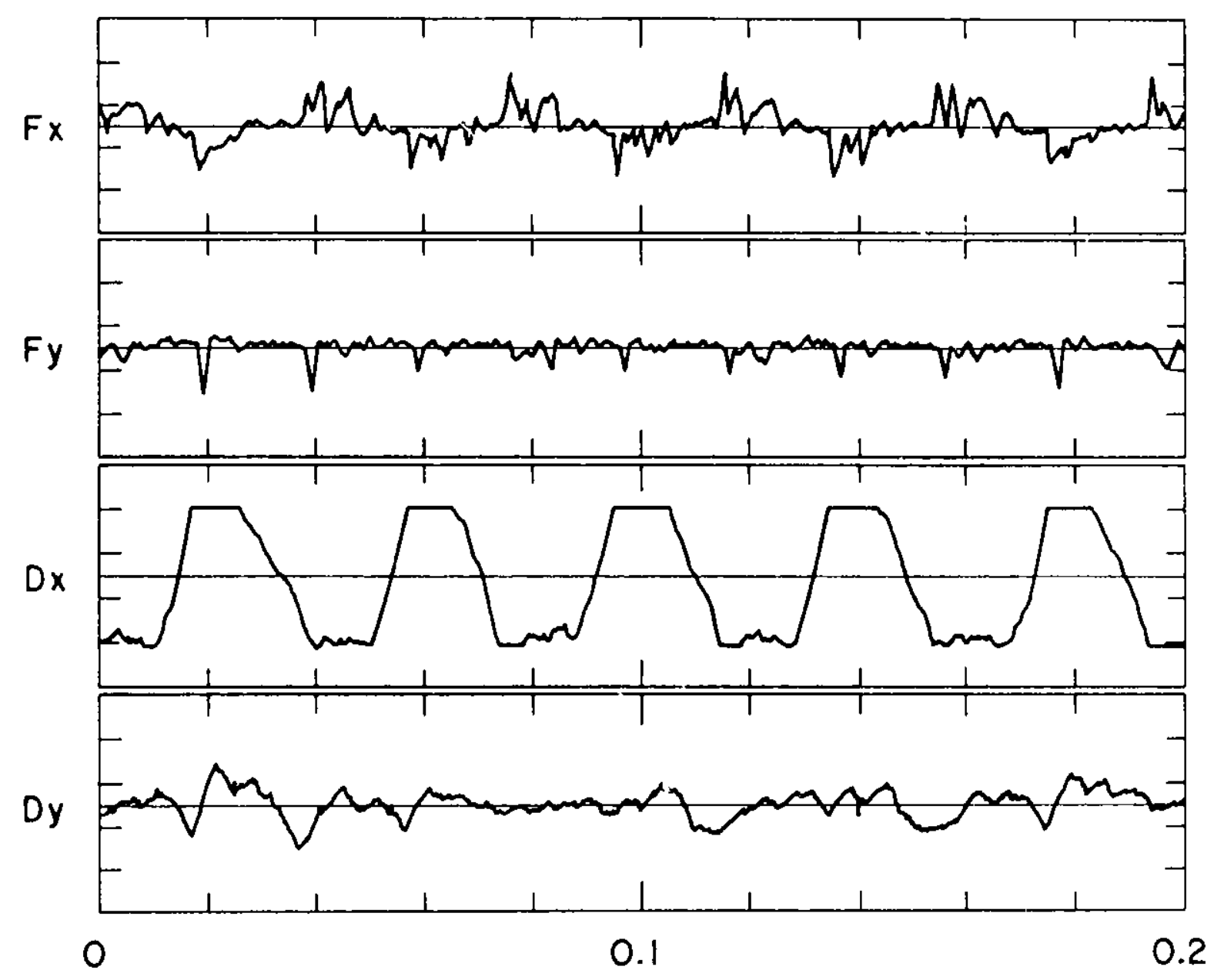

TIME, sec

F1g. 12. Sample of Force and Displacement Records with Preload 


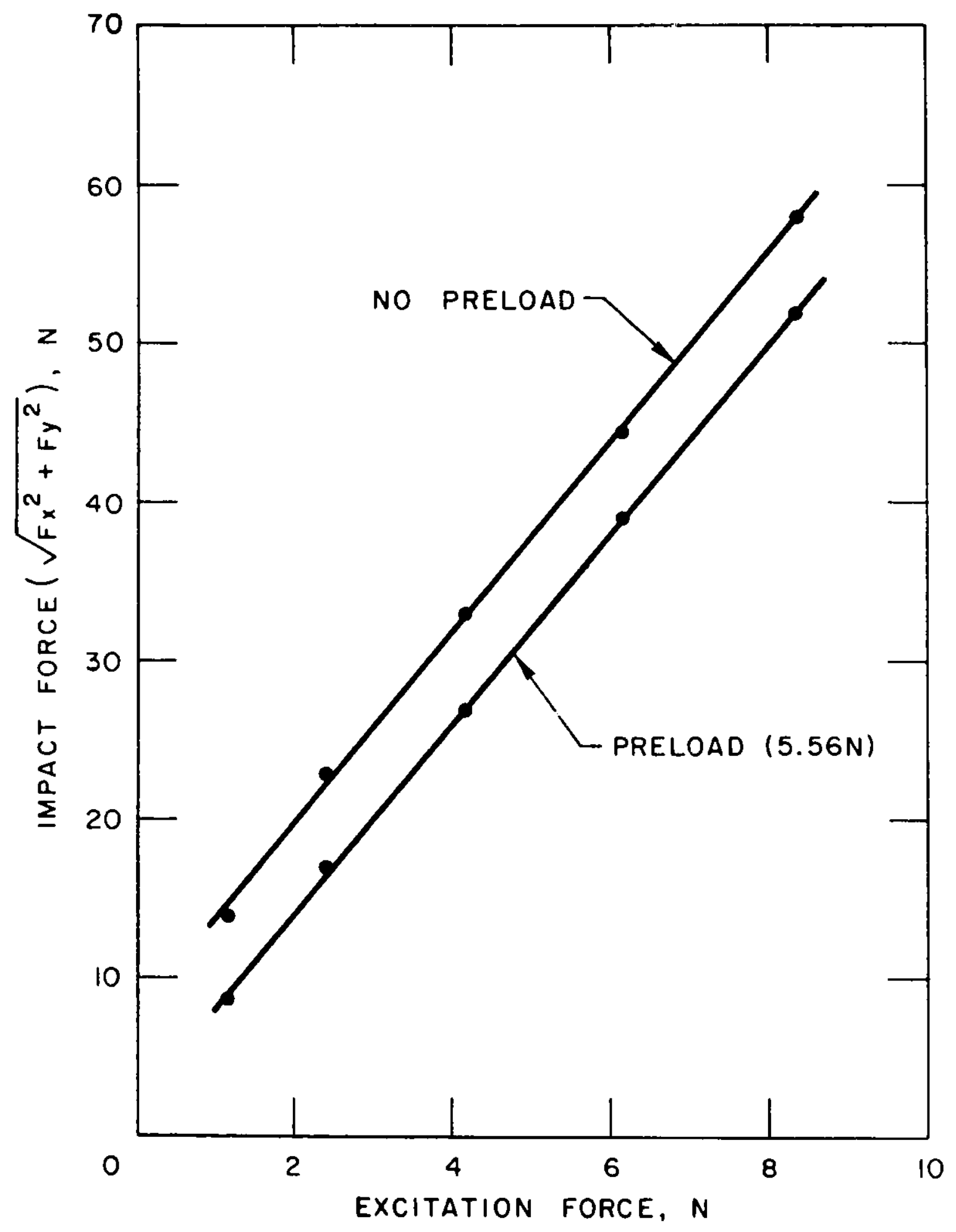

F1g. 13. Impact Force vs. Exc1tation Force at Tube Support Plate 


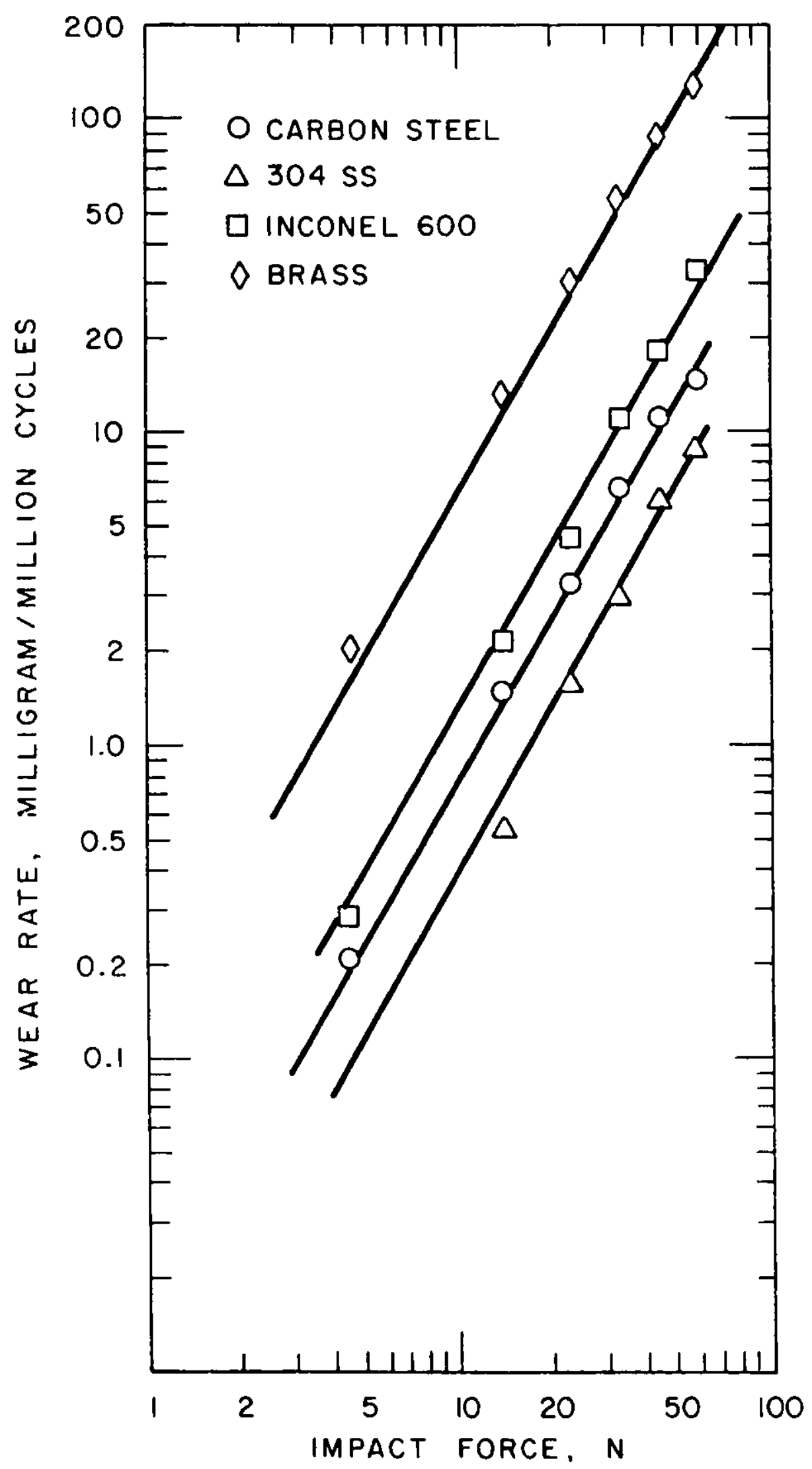

F1g. 14. Wear Rate vs. Impact Force, Frequency: $26 \mathrm{~Hz}$, Tube/TSP Clearance (diametral): $0.78 \mathrm{~mm}$, TSP Th1ckness: $14.27 \mathrm{~mm}$, Preload: None 


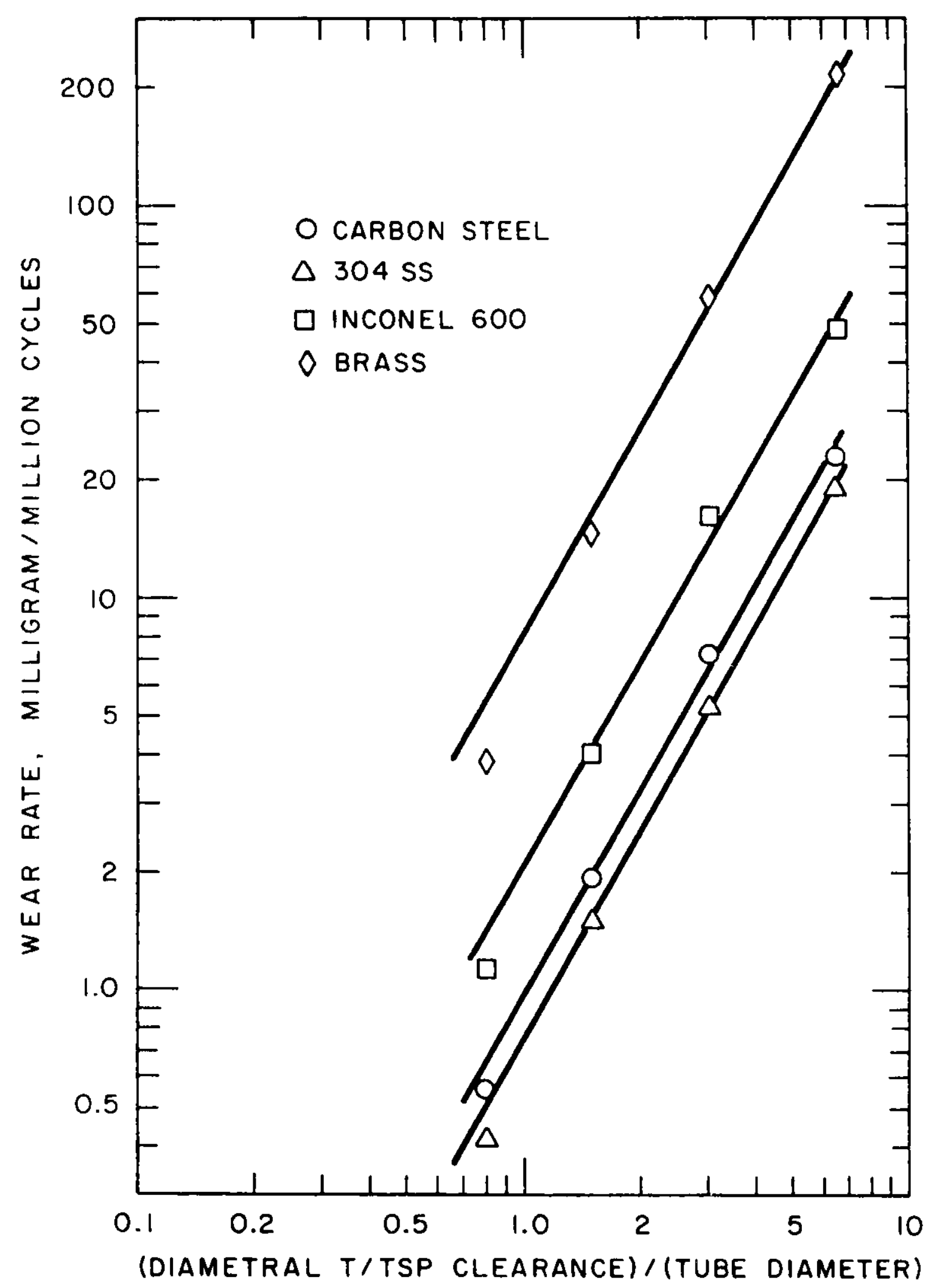

F1g. 15. Wear Rate vs. Tube/TSP Clearance, Excltation Force: $6.14 \mathrm{~N}$, Frequency: $26 \mathrm{~Hz}$, TSP Th1ckness: $14.27 \mathrm{~mm}$, Preload: $5.56 \mathrm{~N}$ 
rate with increasing clearance between tube and support plate hole can be expressed as an exponential relationship, $w=k_{2}\left(C_{d} / D\right)^{2}$, as seen in Fig. 15, where $C_{d}$ is diametral clearance at the support plate, and $D$ is tube outer diameter. It was found that the exponent $a_{2}$ is approximately 1.76 for all four materials and that the constant $k_{2} 180.75$ for 304 stalnless steel, 0.97 for carbon steel, 2.06 for Inconel 600 , and 8.3 for brass.

Force measurements, made with these clearances, show that the support reaction force increases with increasing clearance while the excitation force ard frequency are kept constant; see F1gs. 16 and 17 . These results indicate that increasing the clearance between tube and support plate hole results in larger reaction forces at the support. It follows then that increasing the clearance, increases the wear rate.

D. Tube Support Plate Thickness

To Investigate the effect of tube support plate thickness, tests were performed using tube support plate specimens of three different thicknesses. The tests were performed in alr for four material combinations with fixed excitation force level, excitation frequency, and tube-to-support hole clearance. Figure 18 shows a decreasing wear rate, expressed in terms of loss of tube depth, with increasing thickness of the tube support plate; this agrees with the findings of other investigators $[3,4]$.

During the tests, the 1mpact forces at the support were measured for each tube support plate thickness, however, no consistent force differences could be found. It appears that this finding can be attributed to the effect of higher local stress generation at the smaller thickness tube support plate.

\section{E. Excitation Frequency}

Figure 19 shows the varlation of wear rate, measured on the tube specimen, as a function of excitation frequency for carbon steel with a constant impact force at the support. In the low frequency region $(<40 \mathrm{~Hz}$ ) there is no evidence of a significant frequency effect on wear rate, as also reported by $\mathrm{Ko}$ [3]. In the higher frequency region ( $>40 \mathrm{~Hz}$ ), however, wear rates decrease considerably with increasing frequency. In the frequency range of these experiments, it appears that the wear rate of tube varies hyperbolically with frequency.

The decrease in the fretting wear rate in the higher frequency region can probably be attributed to the decrease in contact time between the two bodies during impacting, as can be seen in Fig. 20. In these test.s, it was found that the contact times were about $0.022 \mathrm{sec}$ per cycle for $26 \mathrm{~Hz}$, and about $0.010 \mathrm{sec}$ per cycle for $40 \mathrm{~Hz}$; for further comparison, the contact time was about $0.005 \mathrm{sec}$ per cycle for $60 \mathrm{~Hz}$. Accordingly, at higher frequencles where the contact time per cycle of excitation is short, the overall weight loss is less. 


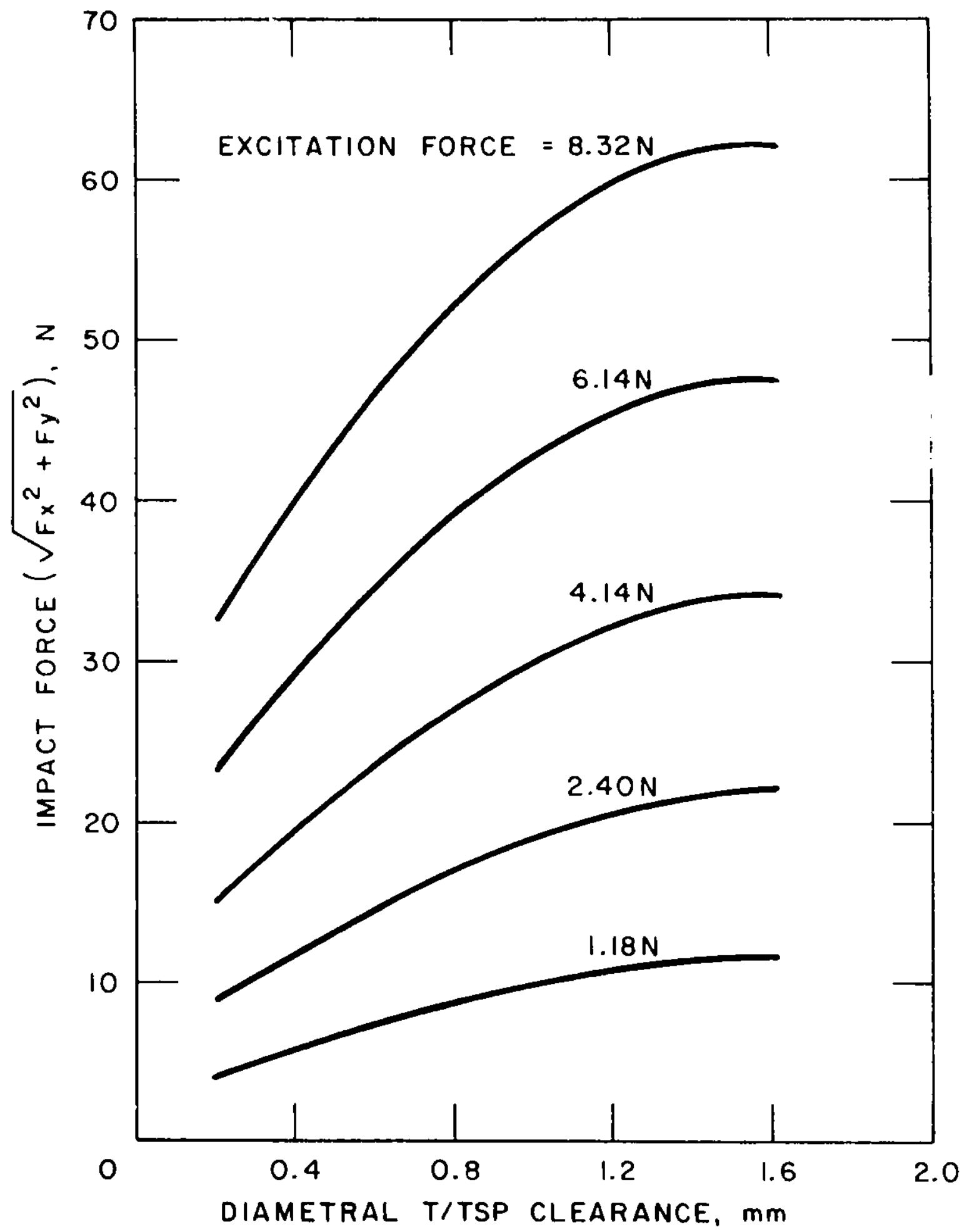

Fig. 16. Impact Force v8. Tube/TSP Clearance without Preload, Frequency: $26 \mathrm{kz}$, TSP Thlckness: $14.27 \mathrm{~mm}$ 


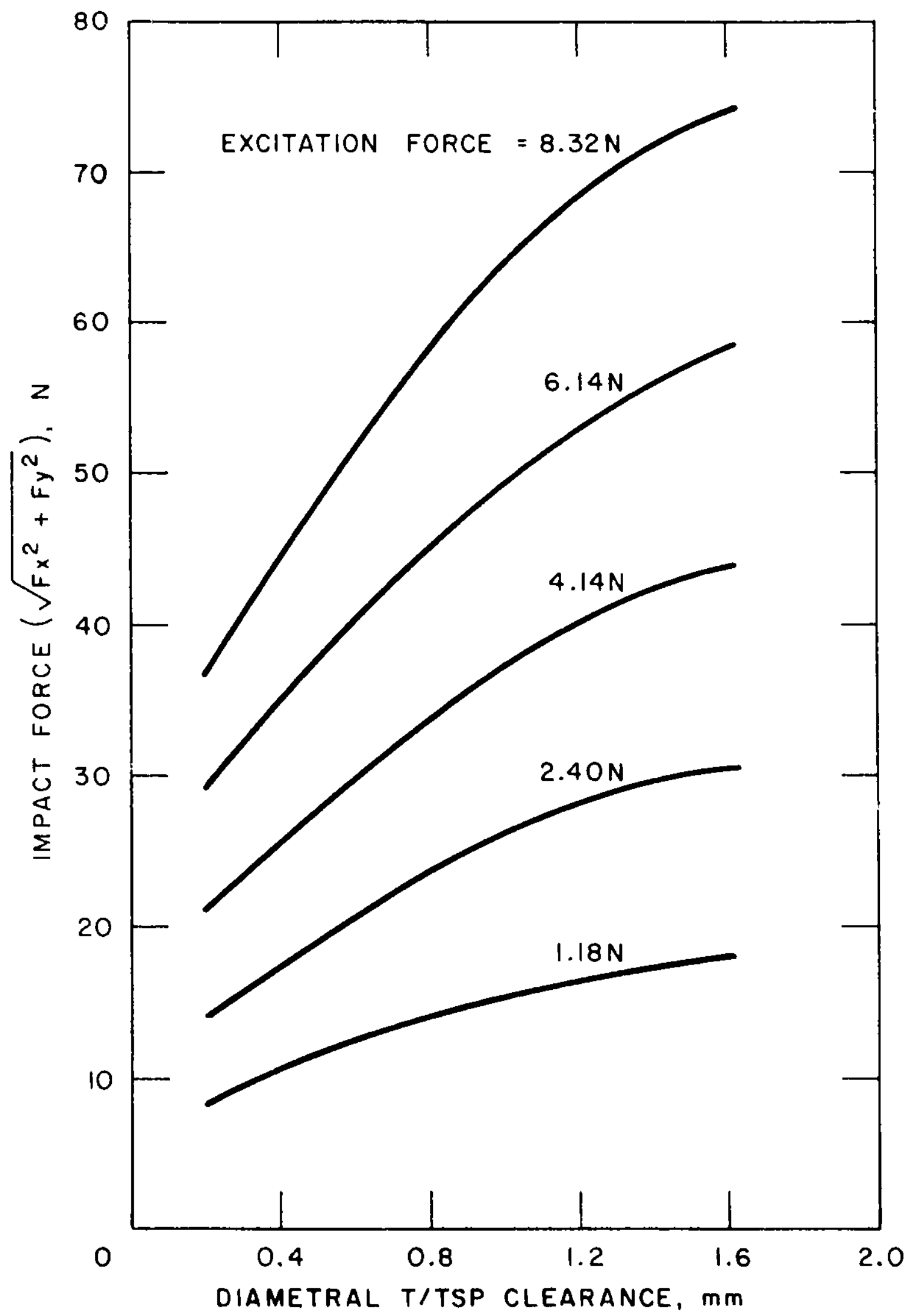

F1g. 17. Impact Force vs. Tube/TSP Clearance with Preload, Frequency: $26 \mathrm{~Hz}$, TSP Thickness: $14.27 \mathrm{~mm}$ 
33

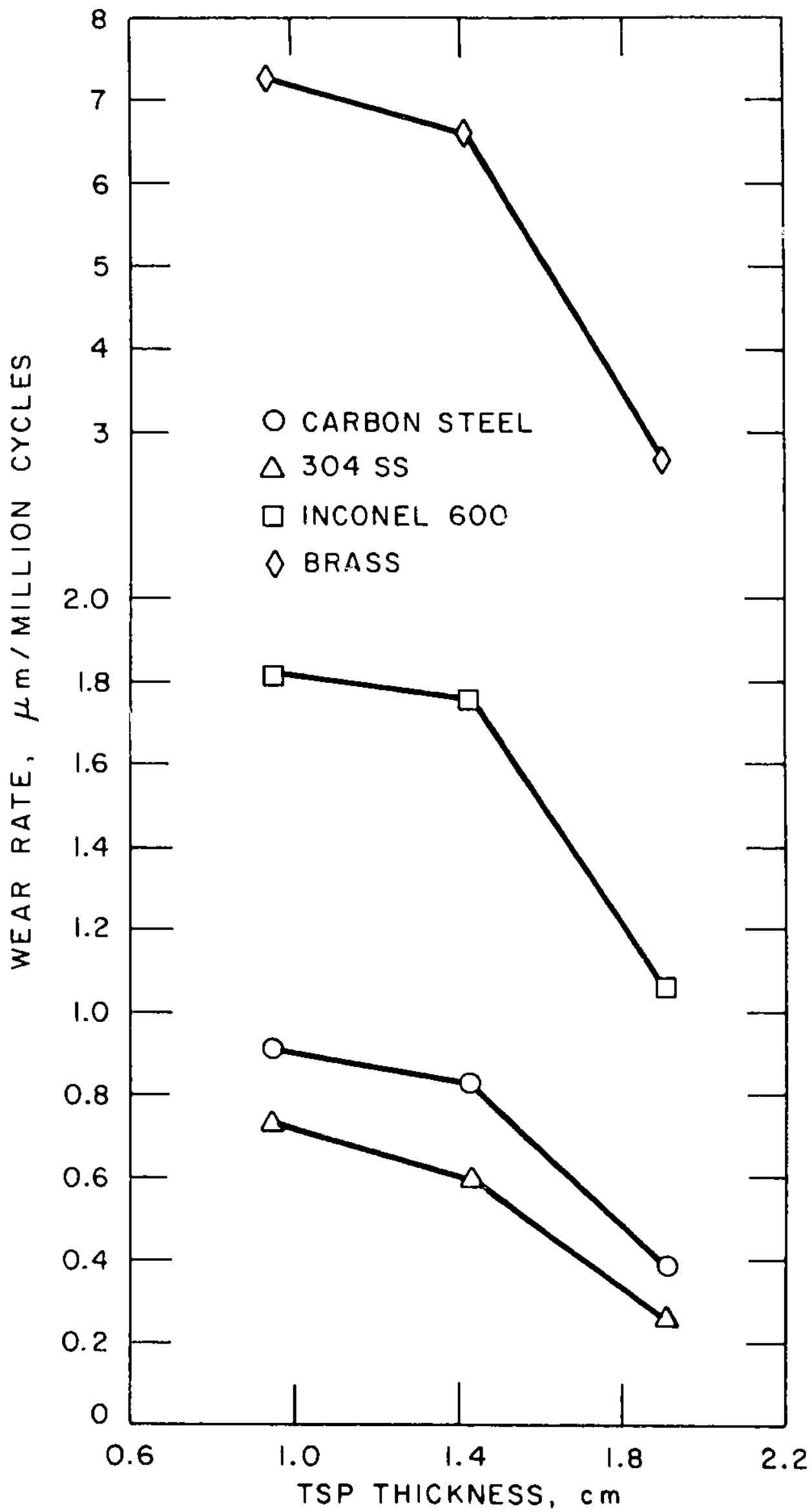

Fig. 18. Wear Rate vs. TSP Thickness, Exc1tation Force: $6.14 \mathrm{~N}$, Frequency: $26 \mathrm{~Hz}$, Tube/TSP Clearance (dianetral): $0.78 \mathrm{~mm}$, Preload: $5.56 \mathrm{~N}$ 


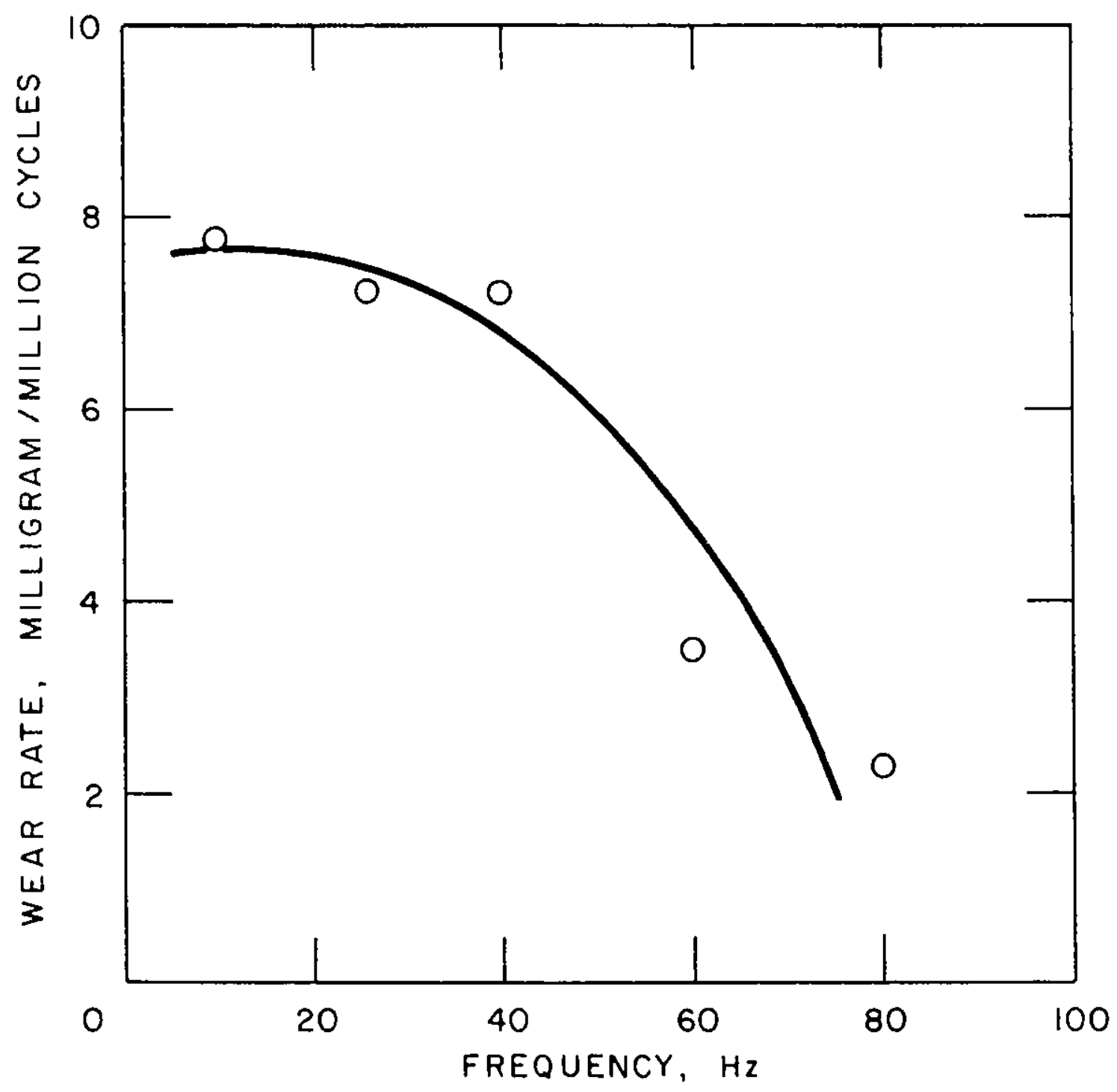

F1g. 19. Wear Rate Vartation with Frequency. Impact Force: $39 \mathrm{~N}$, Tube/ TSP Clearance (dlametral): $0.78 \mathrm{~mm}$, Materlal: Carbon Steel, Preload: $5.56 \mathrm{~N}$ 


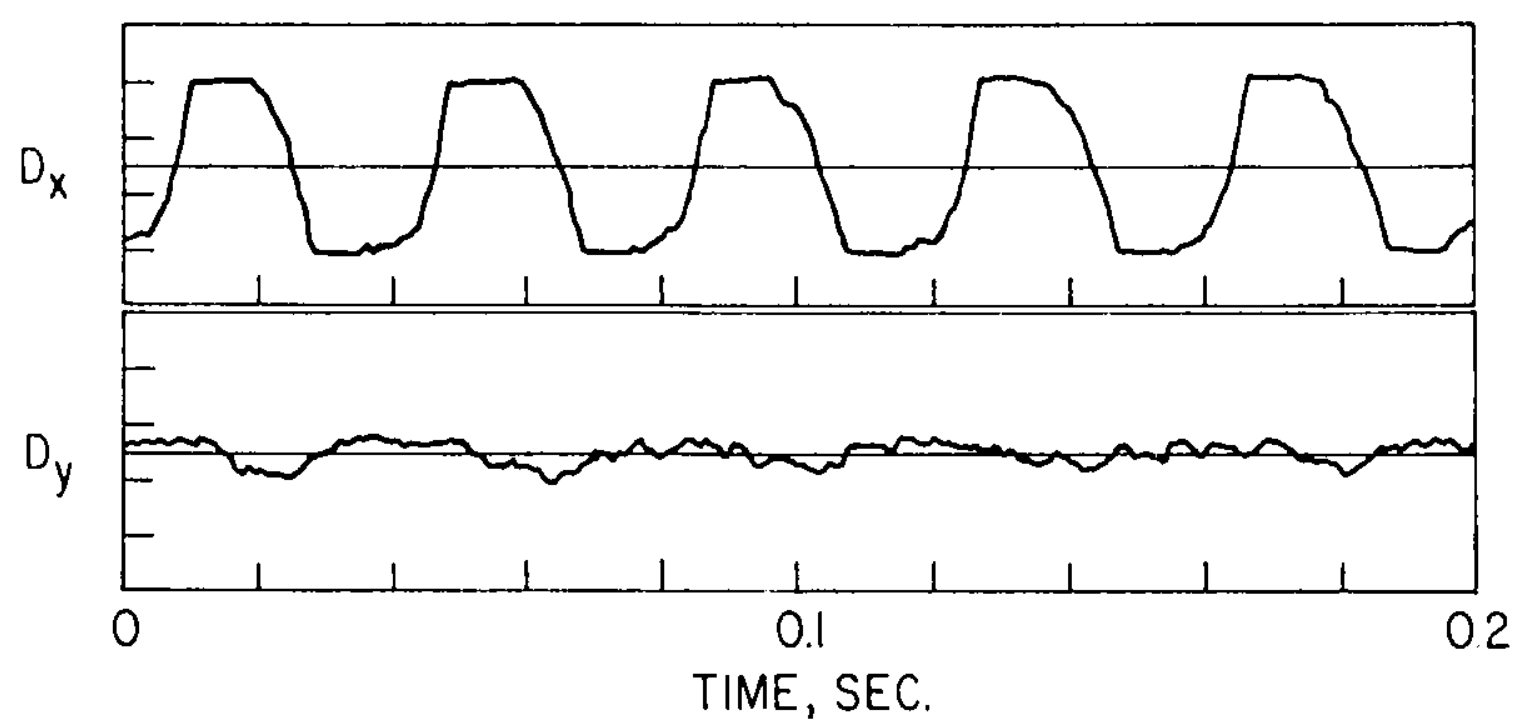

(a) $f=26 \mathrm{~Hz}$

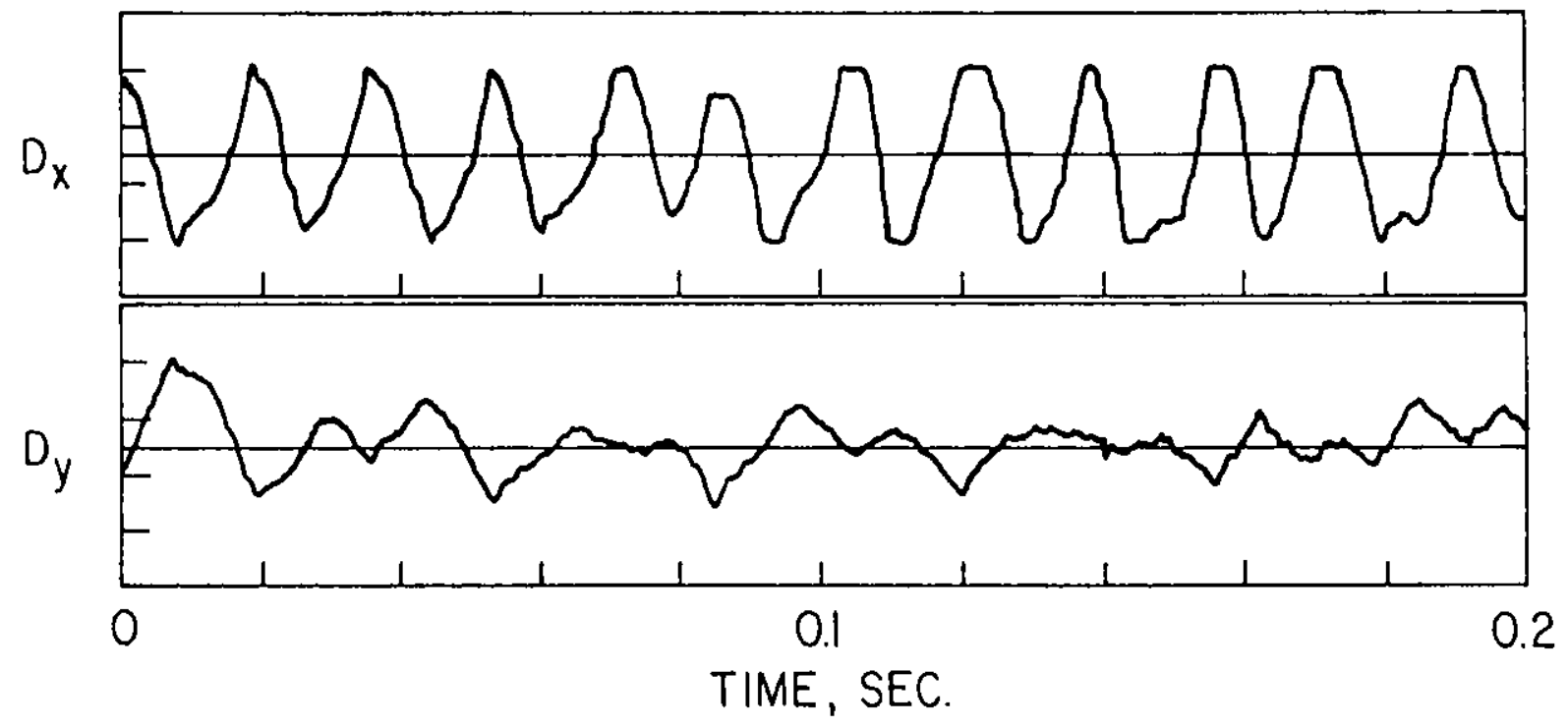

(b) $\mathrm{f}=60 \mathrm{~Hz}$

F1g. 20. Comparison of Displacement Records with Time of $26 \mathrm{~Hz}$ and $60 \mathrm{~Hz}$ 


\section{F. Duration of Test}

The long time duration tests were interrupted with periodic measurement of the wear in order to obtain information on the time dependent wear behavior. The fretting wear rates of the tube specimen as a function of time are shown in Figs. 21 through 25 for various material combinations with fixed excitation force leve1, excitation frequency and tube/TSP geometry. Most of tests were conducted in air; however, some tests were performed in water and o1l. The data points for wear rate at the tube have been taken for the selected time intervals of $1,3,6,24,48,72,98$, and 120 hcurs measured from the starting point. At each interval, the wear specimens were cleaned, welghed, and reinstalled in the test rig in the same orientation as before, and then the test was continued.

The curves in F1gs, 21 and 22 represent wear rates at the tubes for carbon steel/carbon steel, 304 stainless steel/304 stainless steel, Inconel 600 /Inconel 600 combinations, and wear rates at the tube and tube support plate for brass/brass combination. Two trends can be observed from the curves of Figs. 21 and 22. First, the results show that the wear rates for carbon steel/carbon steel and 304 stalnless steel/304 stainless steel combinations decrease with time, while the wear rates of Inconel 600/Inconel 600 and brass/brass combinations increase with time. It appears that the wear rate for an adhesive wear type material decreases with time, while the wear rate for an abrasive wear type of material increases with time.

Generally, the rate of wear shows an initial rapid 1ncrease. However, after 6 hours $(561,600$ cycles) of testing, measured from the starting point, the wear rate gradually decreases or increases with time, dependent on material combination. For some material combinations, the weight losses reach a steady state condition after 98 hours running; see, for example, the 304 stafnless steel/carbon steel combination shown In FIg. 23.

\section{G. Material Combination}

The effects of material combinations on impact/fretting wear can also be observed in Figs. 21 through 25. The curves show that the 304 stainless steel/304 stainless steel combination has the lowest wear rate, and that the brass/brass combination has the highest wear rate. With the exception of the brass/brass combination, 1t was generally found during the tests that tube and tube support plate wear rates are nearly equal when both the tube and tube support plate are made of the same material. The greater weight loss was found for the tube support plate specimen rather than for the tube specimen in the brass/brass comblnation, see F1gs. 21 and 22 . In the brass/carbon steel combination, it can be seen that the wear rate for the brass specimen (tube side) is extremeiy high compared with that for the carbon steel specimen as shown in Fig. 25. It 1s obvious that there are large differences in wear rates between tube and tube support plate spectmens if the tube and tube support plates are of heterogeneous materials as shown in Figs. 23, 24 and 25. It seems that the degree of difference between the wear rates is much more dependent on the material combination than on other parameters. 


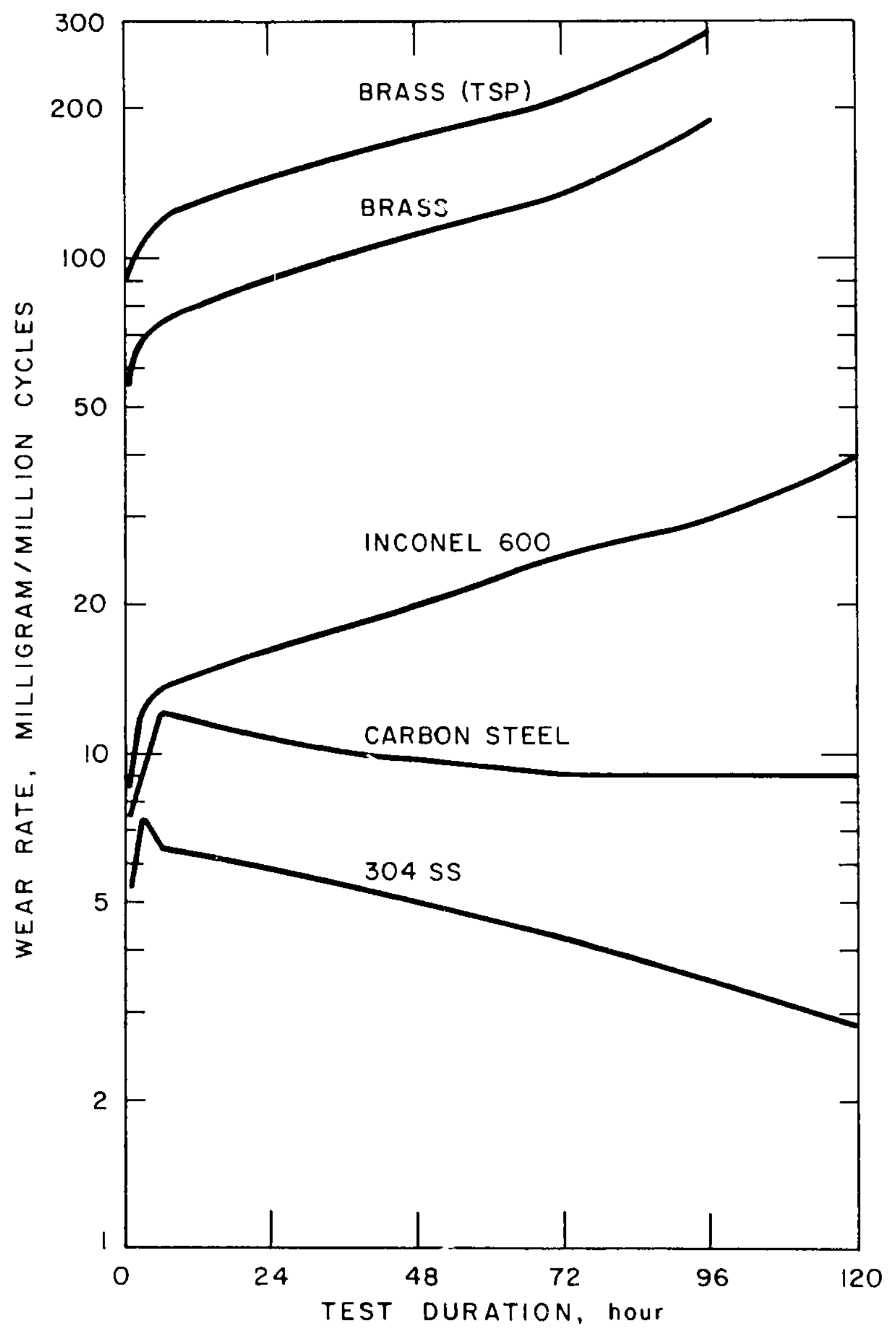

Fig. 21. Wear Rate as a Function of Test Duration, Excltation Force: $6.14 \mathrm{~N}$, Frequency: $26 \mathrm{~Hz}$, Tube/TSP Clearance (diametra1): $0.78 \mathrm{~mm}$, TSP Thickness: $14.27 \mathrm{~mm}$, Preload: None 


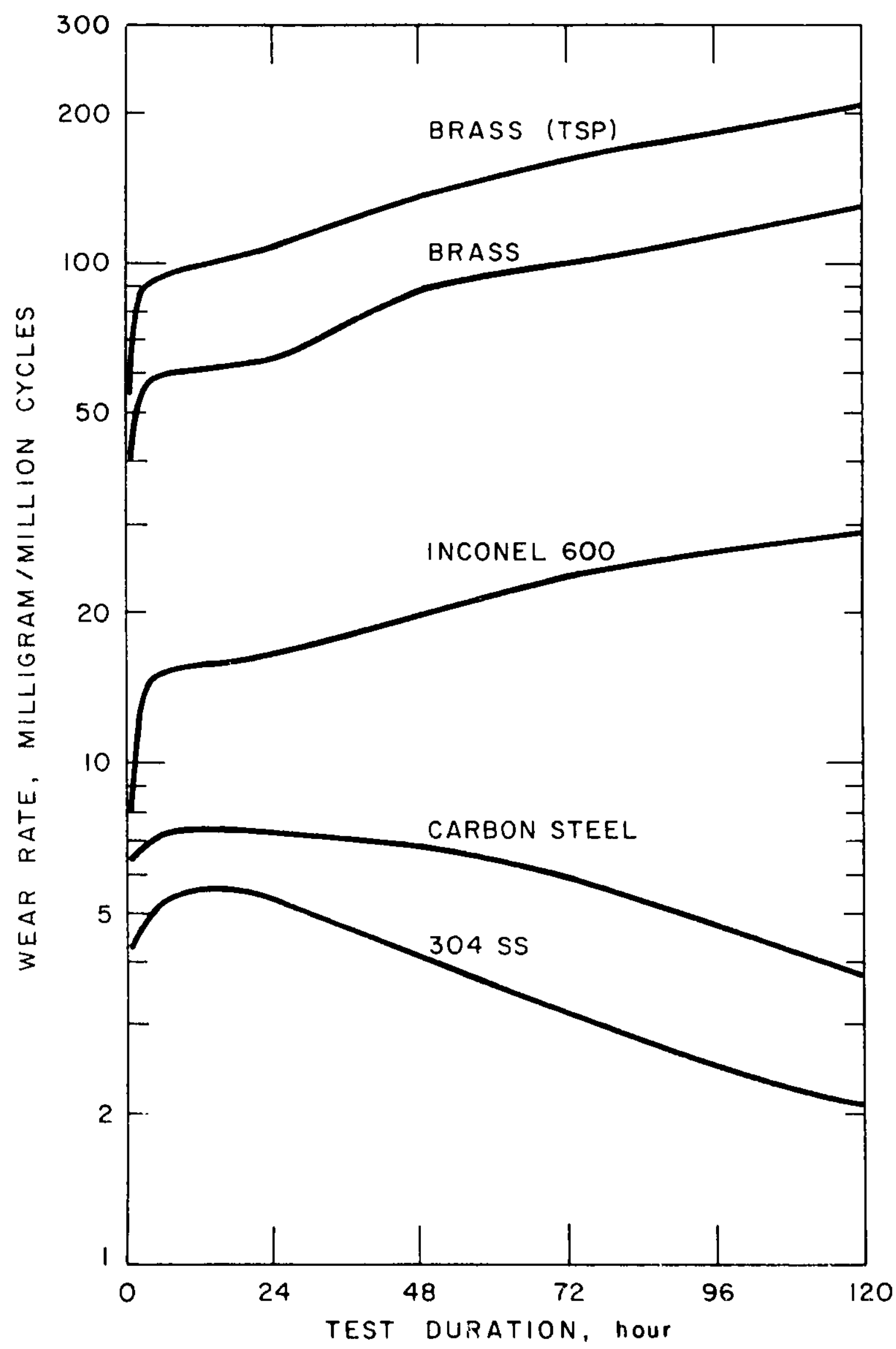

F1g. 22. Wear Rate as a Function of Test Duration, Excitation Force: $6.14 \mathrm{~N}$, Frequency, $26 \mathrm{~Hz}$, Tube/TSP Clearance (diametra1): $0.78 \mathrm{~mm}$, TSP Thickness: 14.27, Preload: $5.56 \mathrm{~N}$ 


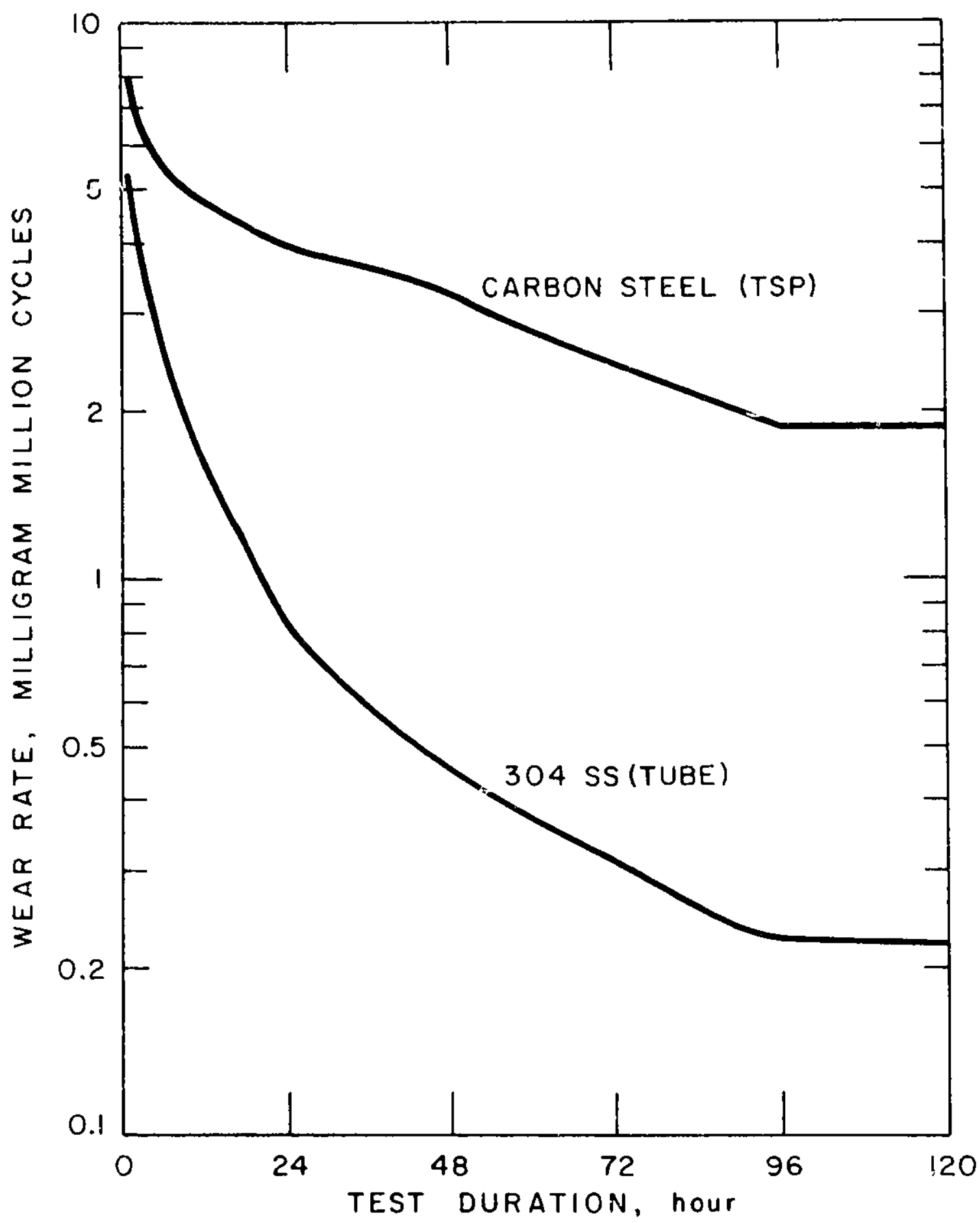

F1g. 23. Wear Rate with Test Duration for Carbon Steel/304 Stalnless Steel Combination, Excitation Force: $6.14 \mathrm{~N}$, Frequency: $26 \mathrm{~Hz}$, Tube/TSP Clearance (diametral): $0.78 \mathrm{~mm}$, TSP Th1ckness: $14.27 \mathrm{~mm}$, Preload: $5.56 \mathrm{~N}$ 


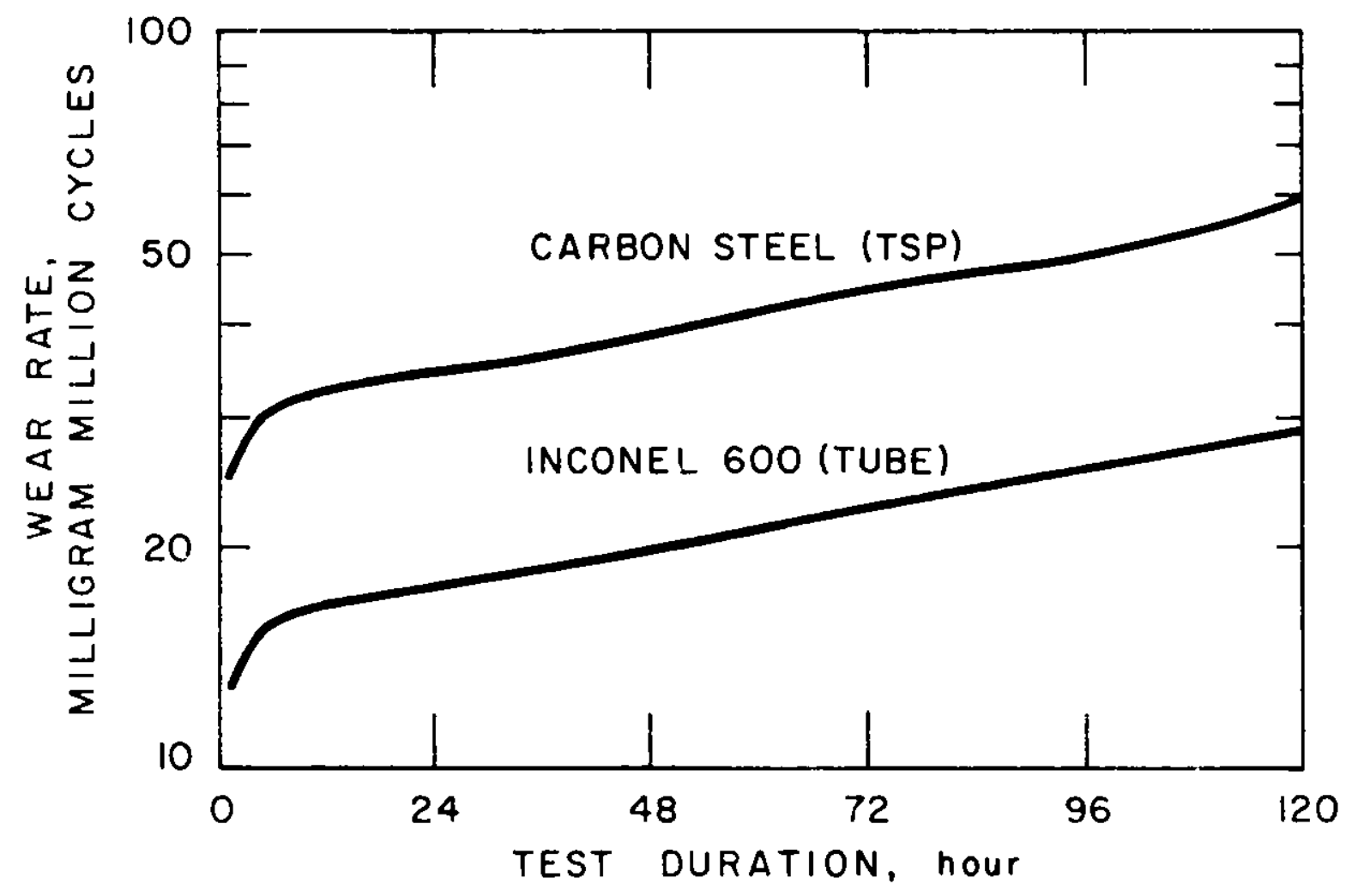

F1g. 24. Wear Rate with Test Duration for Carbon Steel/Inconel 600 Combination, Excitation Force: $6.14 \mathrm{~N}$, Frequency: $26 \mathrm{~Hz}$, Túbe/TSP Clearance (diametral): $0.78 \mathrm{~mm}$, TSP Th1ckness: $14.27 \mathrm{~mm}$, Preload: None 


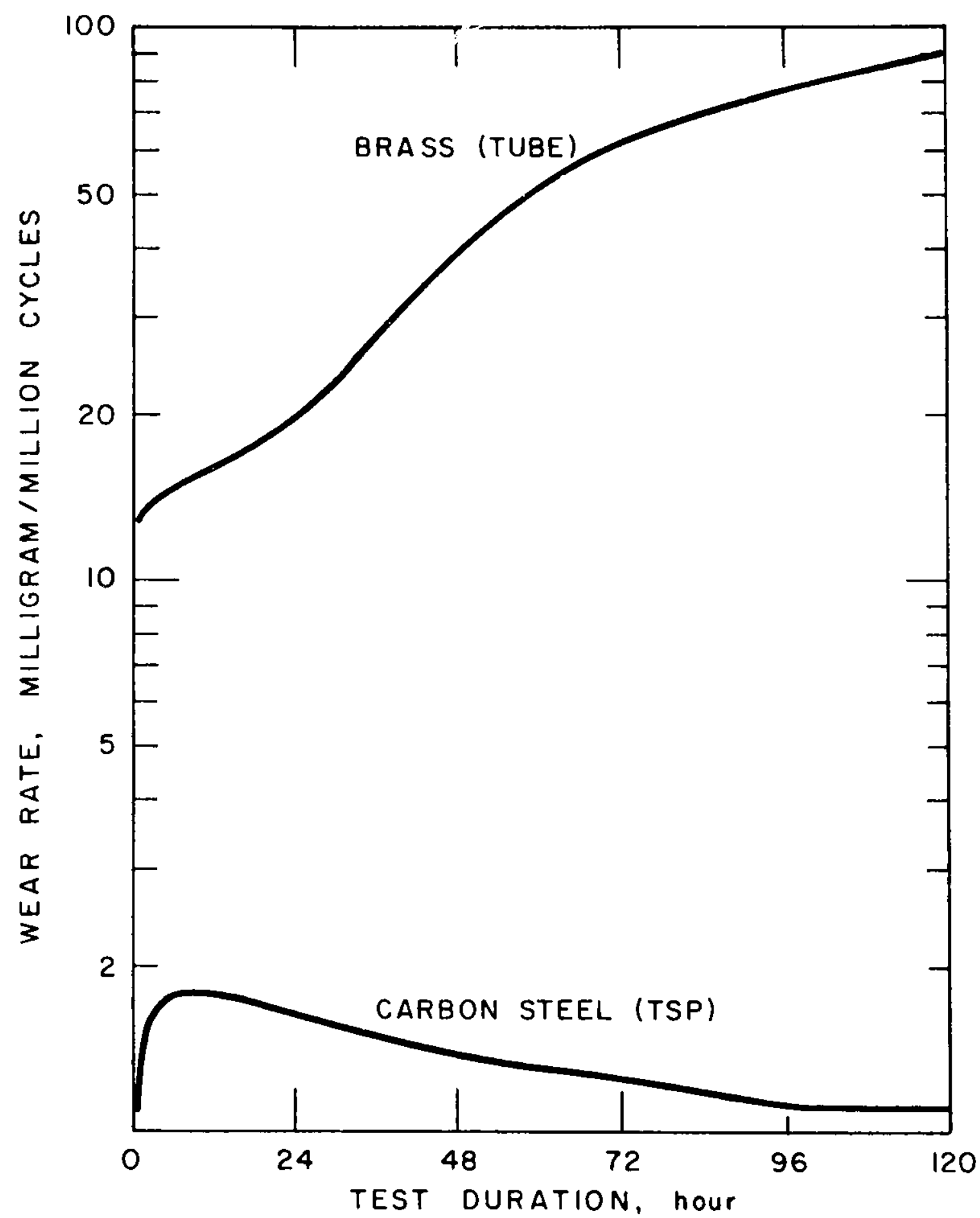

F1g. 25. Wear Rate with Test Duration for Carbon Steel/Brass Combination, Excitation Force: $6.14 \mathrm{~N}$, Frequency: $26 \mathrm{~Hz}$, Tube/TSP Clearance (diametra1) : $0.78 \mathrm{~mm}$, TSP Thickness: $14.27 \mathrm{~mm}$, Preload: $5.56 \mathrm{~N}$ 
When the tube and tube support plate are of same material, no consistent patterns emerged relative to the effect of material hardness. For example, while Inconel 600 has a higher hardness than 304 stainless steel and carbon steel, the wear rate of Inconel 600 is higher compared with both 304 stainless steel and carbon steel. However, there is evidence of material hardness effects when heterogeneous material combinations are used; for example, in the Inconel 600/carbon steel combination (FIg. 24), carbon steel, which has a lower hardness, exhibits a higher wear rate than the higher hardness material, Inconel 600.

In these tests, 304 stainless steel/carbon steel is shown to represent the best material combination. From the impact/fretting wear point of view, the selection of the tube and tube support plate material combination is a very Important consideration in the design of heat exchangers.

\section{H. Liquid Environment}

Impact/fretting wear rates were measured with the specimens submerged in tap water. Comparisons between impact/fretting wear rates measured inafr and in-water at room temperature can be made in Figs. 26 (no preload) and 27 (with preload). These figures indicate that the wear rate in water is higher than that in alr for the same test parameters. It should be noted that the wear rate in water without preload is much higher than the case with preload.

During the in-water tests, a strong pumping effect was observed in the gap between the tube and tube support plate hole. A heavy rusting phenomenon was observed in the water tests. There are no comparison data on the effect of an aqueous fluid on the amount of fretting wear. The accelerated wear may be associated with a washing effect that serves to more easily disperse the debris into the water, as Waterhouse [15] predicts.

An in-oil test using carbon steel/carbon steel combination specimens was attempted with the same parameters as used in the in-water tests. 011 (TEXACO R\&O 150) with a kinematic viscosity of $9.85 \times 10^{-5} \mathrm{~m}^{2} / \mathrm{sec}$ at a temperature of $45^{\circ} \mathrm{C}$ was used. During the first several hours of testing, measurable, but very small, welght loss was observed. However, no quantitative wear was observed during the next 48 hours of testing. The ofl obviously acts as a lubricant, as well as a damping fluld. Jendrzejczyk [16] has reported a larger damping ratio in ofl than in water for tests associated with a study of tube to tube support plate interaction dynamics. Wear can be greatly reduced by proper lubrication, especially when a full hydrodynamic ofl film $1 \mathrm{~s}$ achieved in the gap between the surfaces of two bodies.

\section{DISCUSSION}

Fretting wear is defined as the removal or displacement of material from surfaces of bodies in relative motion by mechanical or mechanical/ chemical processes. Wear of metals is a complex phenomenon. In the past, 


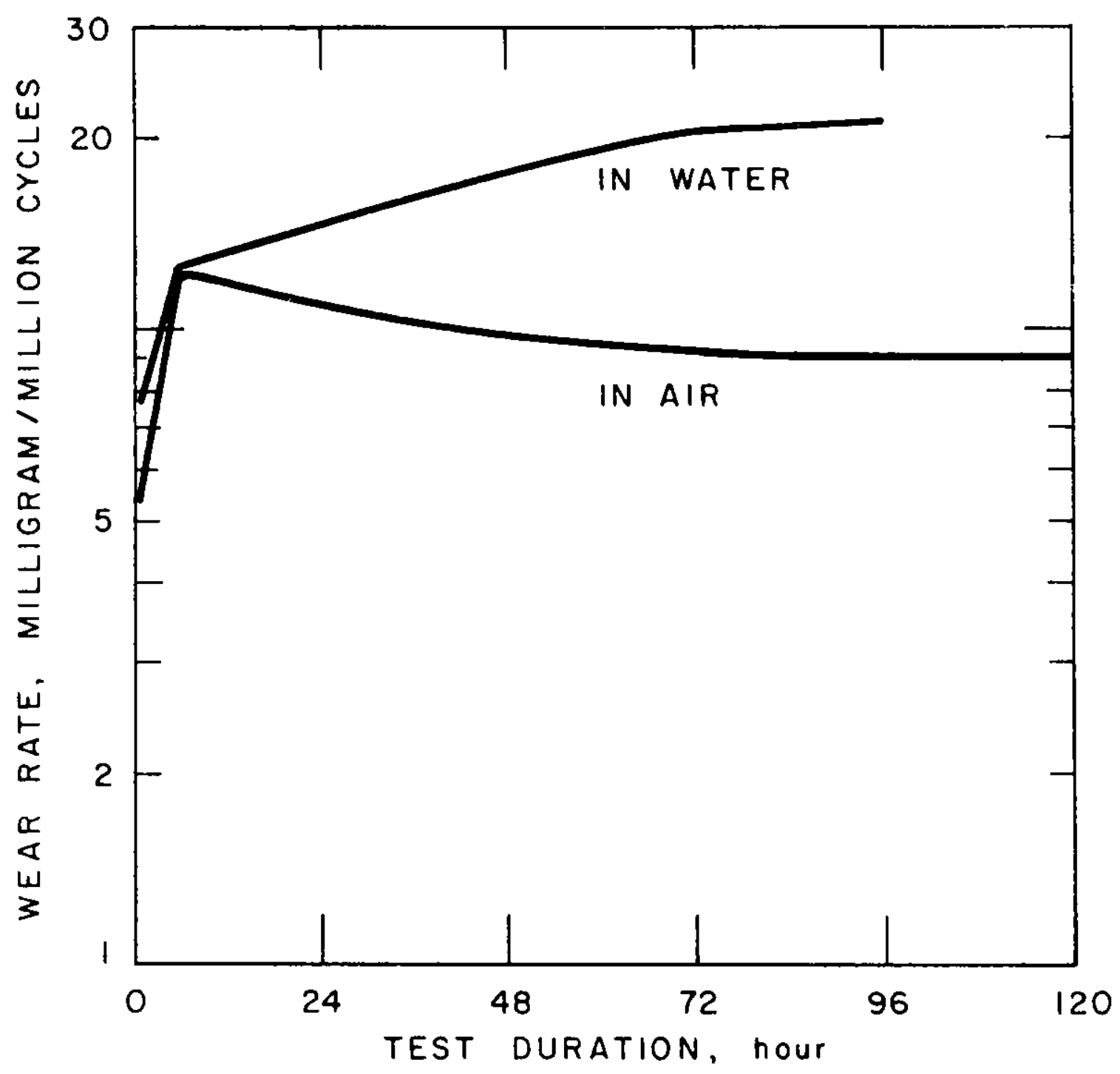

Fig. 26. Comparison of Wear Rates of In-Air and In-Water Tests, Excitation Force: $6.14 \mathrm{~N}$, Frequency: $26 \mathrm{~Hz}$, Tube/TSP Clearance (diametral): $0.78 \mathrm{~mm}$, TSP Th1ckness: $14.27 \mathrm{~mm}$, Material: Carbon Steel, Preload: None 


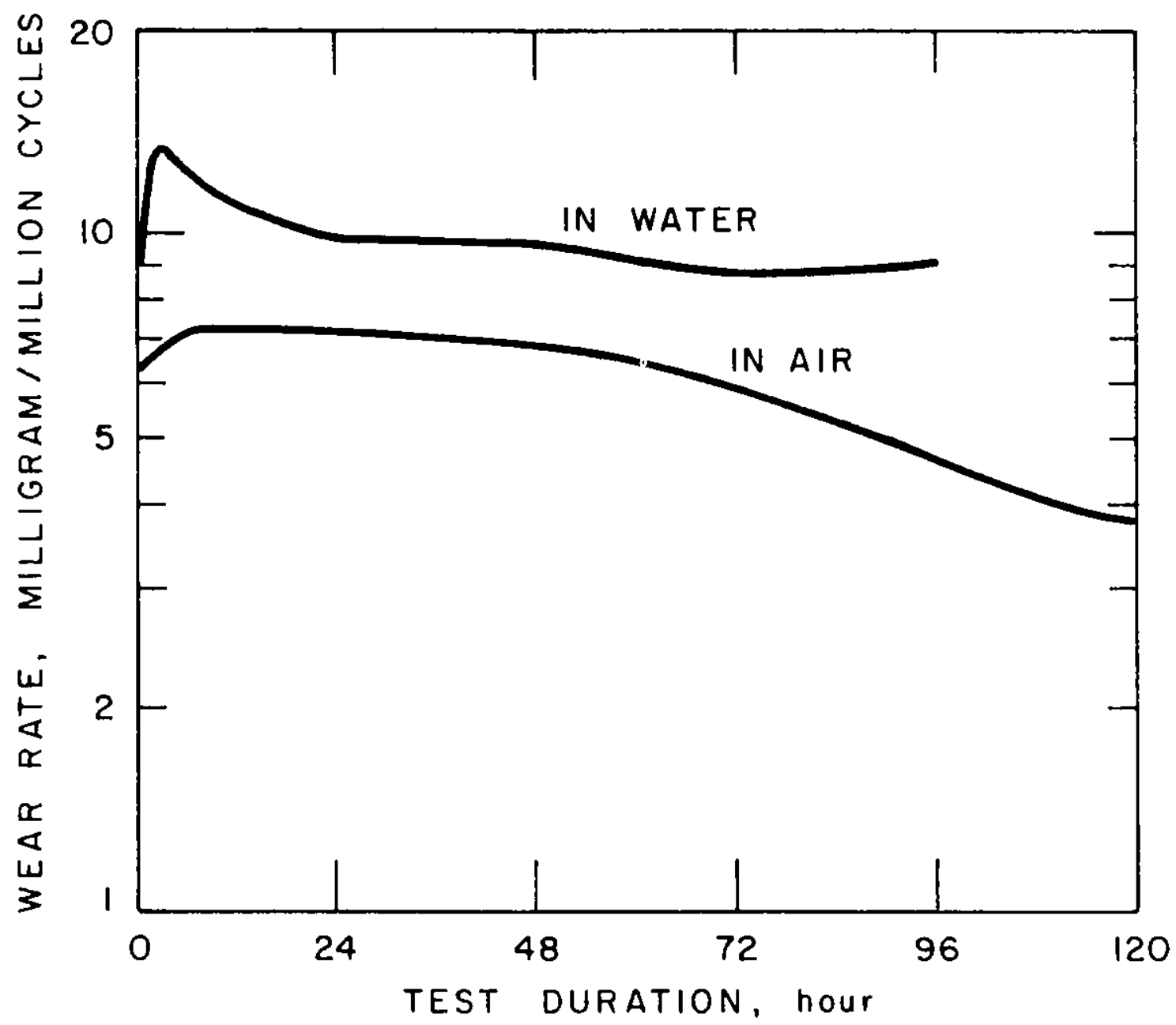

F1g. 27. Comparison of Wear Rates of In-Air and In-Water Tests, Excitation Force: $6.14 \mathrm{~N}$, Frequency: $26 \mathrm{~Hz}$, Tube/TSP Clearance (diametra1): $0.78 \mathrm{~mm}$, TSP Thickness: $14.27 \mathrm{~mm}$, Material: Carbon Steel, Preload: $5.56 \mathrm{~N}$ 
vartous wear mechanisms have been considered: adhesive, abrasive, diffusive, corrosive, fatigue and fretting. The existence of abrasive, diffusive and corrosive wear mechanisms has been reasonably well established, however, the mechanisms of adhesive, fatigue and fretting wear are not clearly understood yet. Fretting wear is a combination of adhesive, abrasive and corrosive mechanisms, and is often connected with ciie appearance of surface fatigue.

Several investigators have described the possible processes involved in freti.tng wear. For example, Waterhouse [17] presented the following steps: removal of metal from the surfaces by mechanical grinding action or by formation of welds followed by tearing; oxidation of the metal particles into an abrasive powder which continues the action; oxidation of the metal surface; and continual removal of the oxide layer with fresh metal beling exposed. Hurricks [18] described the fretting wear process in the following three steps: (1) intial adhesion and metal transfer; (2) production of debris in a normally oxidized state; and (3) steady-state wearing.

Based on the results of these experiments, various time-dependent stages in the fretting wear process can be proposed. It seems that the wear process consists of the following stages: initial preparatory stage for wear formation by the oscillating impact force; transient stage involving plastic deformation, metal transfer, and oxldization; and stable (steady state) stage for continuous generation of wear debris.

The results of Figs. 21 and 22 show that the wear rate assoclated with the Inital stage, consisting of several thousands cycles, is very low. Once two metallic surfaces are brought into contact under oscillating 1mpact conditions, they are initially protected by an oxide-metal surface layer. Th1s oxide layer can act as a solid lubricant film in preventing metal-tometal contact. During the inftial perfod, it is belleved that there is a pile-up of dislocations a fintte depth below the surface. Suh [19] suggests that this leads to the formation of voids, to the coalescence of the volds by shearing of the metal, and, ultimately, to plastic deformation. In the transient stage, the apparent virgin material is deformed at the surface; the adhesion and metal transfer processes then follow. The disruption of the protective oxide film allows the oxidation of next layer to occur. Due to break-up of the surface by severe surface fatigue, the wear rate is higher during this period. The degree of plastic deformation and adhesion depends on the impact force and on the metallurgical properties of the materials. After the transient period, the wear rate stabilizes. The stable state is defined as that point in the wear process at which the loss of debris from the specimen boundaries is a constant with time.

After reaching the stable state, there are two t1me-dependent trends associated with the wear rate, as discussed in a previous section. Wear rates of Incone 1600 and brass increase with time, 1.e., the time exponent 1s greater than 1; wear rates of carbon steel and 304 stainless steel decrease with time. Figure 28 shows the appearance of the worn surface of the brass tube specimen after 120 hours of impact/fretting wear. A severely damaged surface, Indicative of falrly large size debris, is shown. 


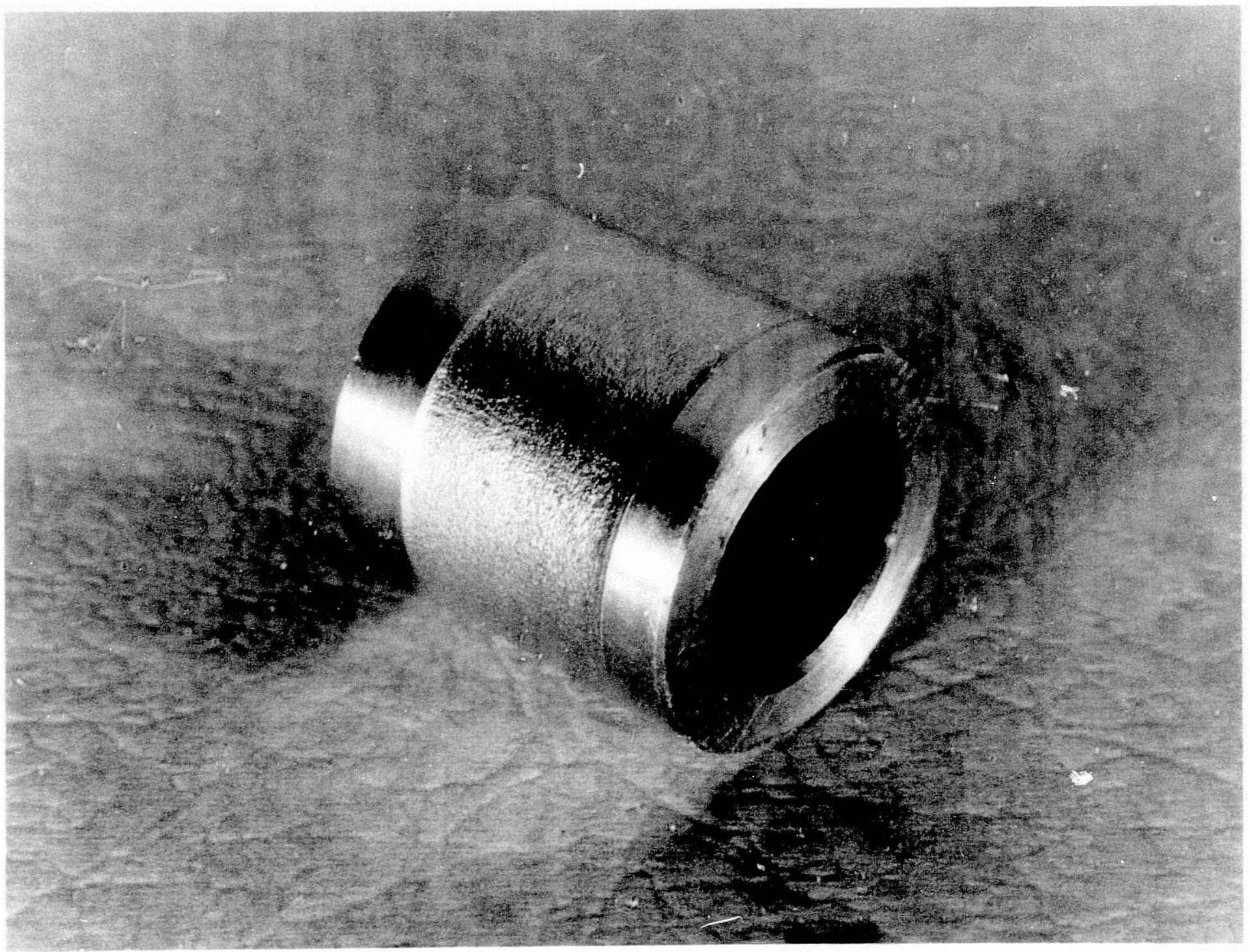

宓

Fig. 28. Appearance of a Worn Tube Specimen (ANL Neg. No. 113-85-14) 
Figures 29 and 30 show, respectively, the scanning electron microphotographs of the damaged surfaces of a 304 stainless steel and an Inconel 600 tube specimen following impact/fretting wear. Figure 29, for the case of 304 stainless steel, shows a structure of relatively fine surface flakes. It appears to have been polished by a fine adhesive action with weak abrasion involved. Due to the work hardening effect by the osclllatory 1mpact action, it seems that the wear rate is decreased with time. Materials that are both hard and ductile, such as stalnless steel, are the best from a wear resistance standpoint. On the other hand, Fig. 30 for Inconel 600, shows the size of the surface flakes on the specimen to be comparatively larger than those for 304 stainless steel. It appears that in this case the damage has been enhanced by the abrasive action of oxidized wear particles of fairly large size.

As shown in the 1n-water test, the effect of an aqueous fluid is to enhance the fretting wear rate since dispersal of the debris occurs more easily in a liquid and, thereby, allows the chemical processes, for example, oxidation, to occur. Uhlig [20] suggests that the mechanism of fretting wear Includes a chemical factor as well as mechanical factor. Since rusty water was observed during the in-water tests, it seems certain that the fretting wear involved a chemical process as a chemical reaction product is formed.

The study of fretting wear is influenced by many variables and a number of theorles have been proposed to explain the observed effects. However, it. appears that no one theory of fretting wear can be established as correct to the exclusion of others.

An empirical formula for fretting wear has been developed for use in impact/fretting wear calculations. The formula is based on the experimental data from these tests and accounts for varlations in fretting wear due to vibration with the following parameters:

(1) Impact force between tube and tube support plate. The results confirmed that impact/fretting wear is malnly dependent on the impact force. The results also show that the impact force is a function of the clearance between tube and tube support plate hole.

(2) Frequency of tube vibration. The results of the test show that the wear rate depends on frequency of vibration.

(3) Duration of fretting wear process. The results indicate that the wear rate varies with time duration of impact/fretting. The time exponent depends on the material combination and environment.

The following form was chosen Eor an empirical formula to correlate the experimental data for the impact/fretting wear rate due to vibration at a particular time,

$$
\mathbf{w}=\mathrm{kF}^{\mathrm{a}} \mathbf{f}^{\mathrm{b}} \mathrm{t}^{\mathrm{c}}
$$




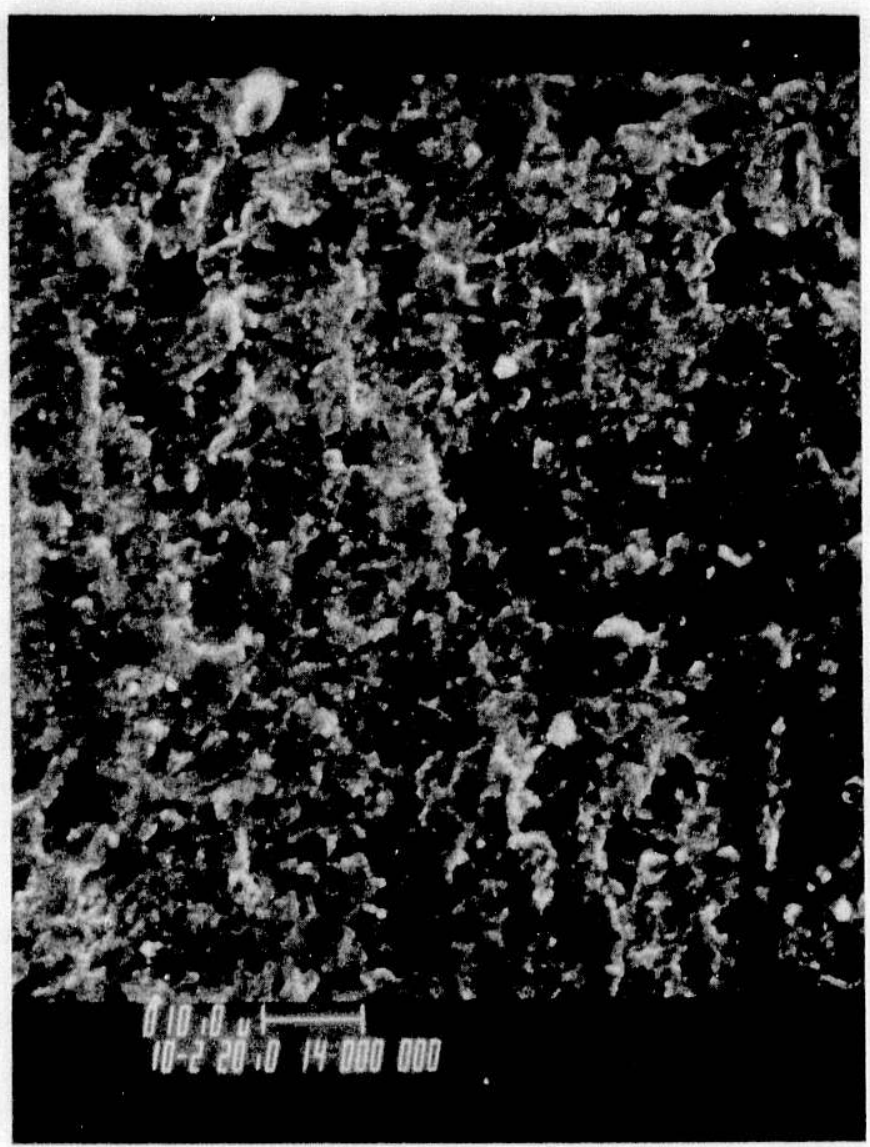

F1g. 29. Microphotograph of a Worn Surface of 304 Stainless Steel Tube Specimen ( $x$ 1000) (ANL Neg. No. 113-85-29) 


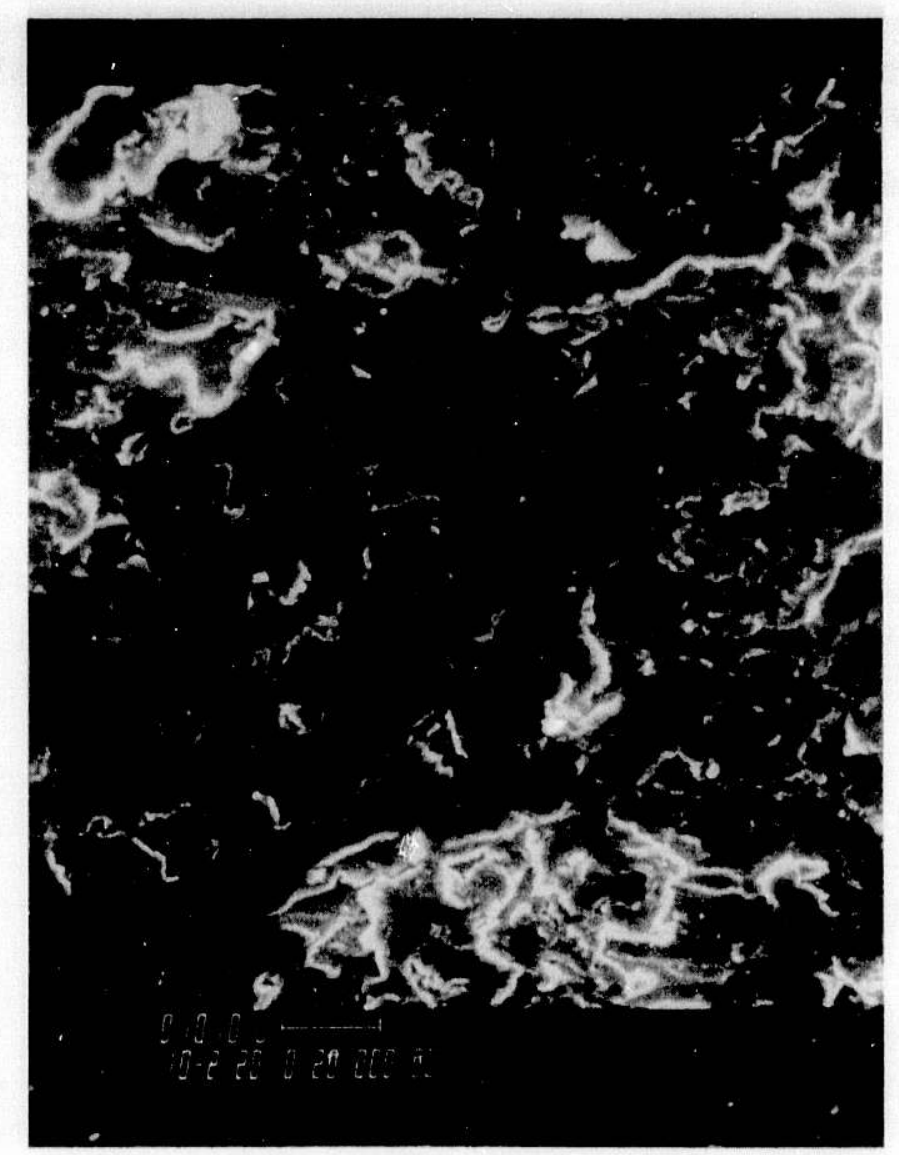

Fig. 30. Microphotograph of a Worn Surface of Inconel 600 Tube Specimen ( $x$ 1000) (ANL Neg. No. 113-85-30) 
where $w$ is the wear rate $\left(\mathrm{mg} / 10^{6}\right.$ cycles) at time $t$ (hour) from starting point, $F$ is the resultant impact force between the tube and tube support plate $(\mathrm{N})$, $\mathrm{f}$ is the frequency of vibration $(\mathrm{Hz})$, and $\mathrm{k}, \mathrm{a}, \mathrm{b}$, and $\mathrm{c}$ are empirically derived constants. This relationship includes the dependence of wear rate on impact force between the wear couple, the frequency of vibration, and the wear processing time.

For a particular frequency of vibration, the wear rate at a selected time from the start of the wear process, can simply be expressed as

$$
\mathbf{w}=\mathbf{k}^{\prime} \mathbf{F}^{\mathrm{a}}
$$

where $k^{\prime}$ is constant.

Generally, impact force $F$ is a function of excitation force $E$ and clearance between tube and tube support plate hole $C_{d}$, i.e.,

$$
F \propto E^{d} C_{d}^{e}
$$

where $d$ and e are empirically derived constants.

Equation (1) does not include the amplitude of vibration since 1 ts magnitude is equivalent to the magnitude of the clearance between the wear couple as long as contact between the two bodies is occurring. The constants $k$ and $c$ are mainly dependent on the material combination and the environment.

For a particular material comblnation and environment, the constants in Eq. (1) can be derlved by fitting the experimental data. As an example, for the wear rate of carbon steel in alr, the following constants were obtalned: $\mathrm{k}=0.8\left(\mathrm{~g} \cdot \mathrm{N}^{-1} \mathrm{~h}-1 \mathrm{cycle} \mathrm{e}^{-2}\right), \mathrm{a}=1.72, \mathrm{~b}=-1, \mathrm{c}=-0.23$. This curve fit is compared with the experimental data in Fig. 31.

\section{CONCLUSIONS}

A series of tests has been performed with the objective to further the understanding of impact/fretting wear of a heat exchanger tube vibrating within a tube support plate hole. Tests were conducted in alr, water, and oil, at room temperature. Wear was measured by a weight loss technique and wear rate was calculated.

The principal results of the tests are: (1) Wear rate increases with tube support impact force; (2) The degree of wear rate is strongly dependent on the metallurgical characteristics of the materials (for example, 304 stainless steel as a tubing material is superior to others with respect to wear resistance); (3) Wear rate is time dependent (for example, for the same excitation conditions, the wear rate of 304 stalniess steel decreases with 


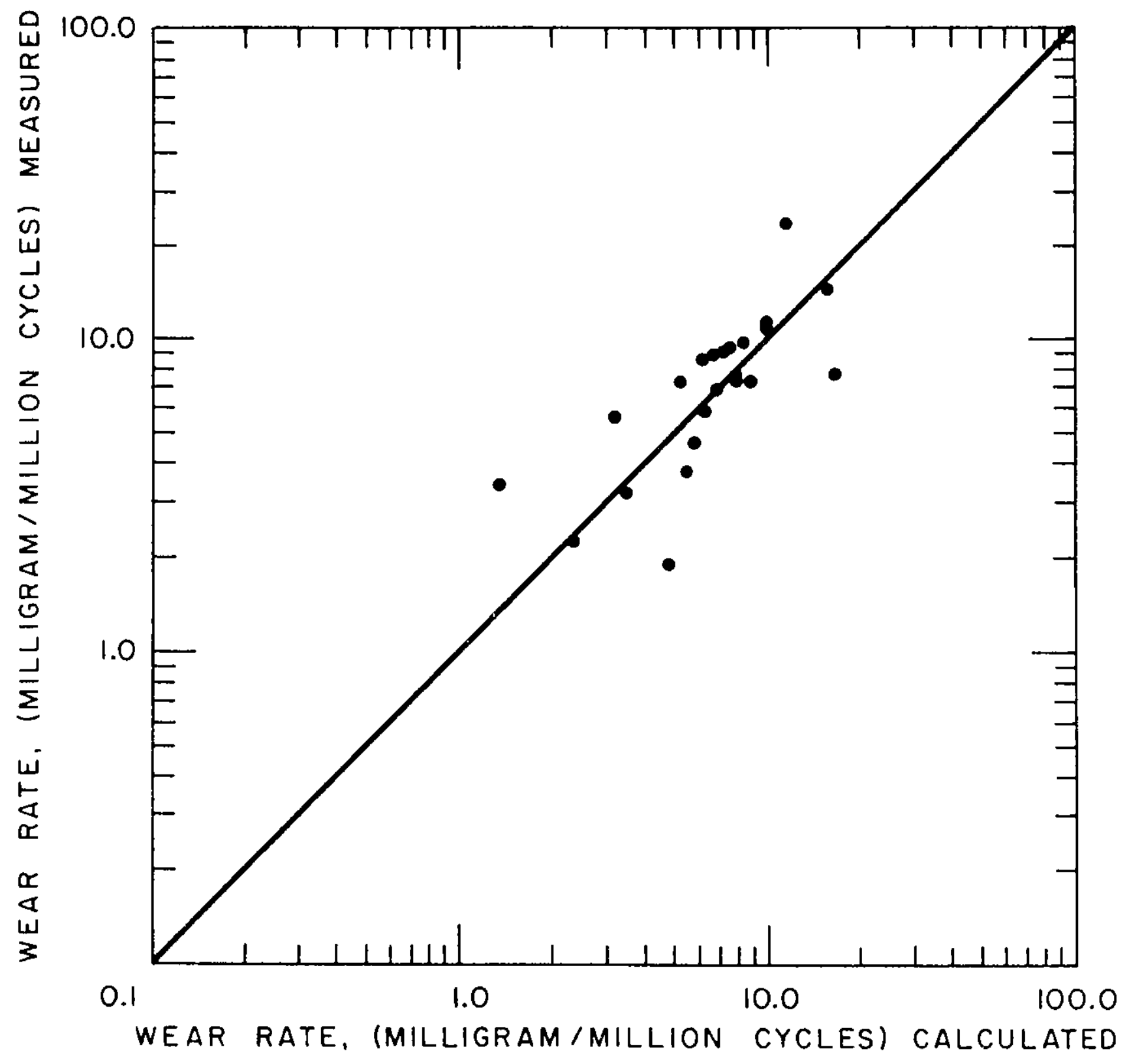

F1g. 31. Comparison of Experimental Data and Empirical Curvefit of Eq. (1) for Carbon Steel/Carbon Steel Combination in Air 
time, whereas Inconel 600 shows an Increase); (4) Impact/fretting wear rate decreases with increasing excltation frequency for a fixed inpact force level at the support; (5) The wear rate for carbon steel in water is greater than that in-a1r, on the other hand, the wear rate in 011 is very much lower than that for other materials; (6) Wear rate decreases with preload of the tube against ie support.

Further investigations are needed to: (1) Identify and characterize the wear producing impact force in real heat exchangers; (2) generate and characterize more basic wear data on varlous material combinations of tube and tube support plate, (3) generate data under operating conditions (temperature and pressure) using autoclaves.

\section{ACKNOWLEDGMENTS}

The work was made possible through the support of the Korea Sclence and Engineering Foundation and was performed as part of a Proyram of She11 and Tube Heat Exchanger Research sponsored by the U.S. DOE Office of Energy Systems Research, Energy Conversion and Utilization Technologies Division.

The authors wish to thank Dr. H. M. Chung for h1s assistance in providing the scanning electron microphotographs. 


\section{REFERENCES}

1. H. Halle, J. M. Chenoweth, and M. W. Wambsganss, "DOE/ANL/HTRI HEat Exchanger Tube Vibration Data Bank," ANL-CT-80-3, Addenda 1-4, 19811983.

2. I-Ming Feng and Herbert H. Unl1g, "Fretting Corrosion of Mild Steel in Atr and in Nitrogen," J. of Applled Mechanics, Vol. 21, Trans. ASME, Vol. 86, pp. 395-400, 1954.

3. P. L. Ko, "Experimental Studies of Tube Frettings in Steam Generators and Heat Exchangers," Trans. ASME, J. of Pressure Vessel Technology, Vol. 101, pp. 125-133, 1979.

4. R. D. Blevins, "Fretting Wear of Heat Exchanger Tubes, Part 1: Experiments," Trans. ASME, J. of Engineering for Power, Vol. 101, pp. $625-629,1979$.

5. R. D. Blevins, "Vibration-Induced Wear of Heat Exchanger Tubes," Trans. ASME, J. of Eng.tneering Materials and Technology, Vo1. 107, pp. 61-67, 1985.

6. S. S. Chen, G. S. Rosenbeig, and M. W. Wambsganss, "On Tube-Baffle Impact During Heat Exchanger Tube Vibrations," Proc. ASME Symp. FlowInduced Vibration in Heat Exchangers, New York, pp. 28-35, 1970.

7. Y. S. Shin, D. E. Sass, and J. A. Jendrzejczyk, "Vibro-Impact Responses of a Tube with Tube-Baffle Interaction," Trans. CSME, Vol. 5, pp. 15-23, 1979.

8. R. J. Rogers and R. J. PIck, "On the Dynamtc Spatial Response of a Heat Exchanger Tube with Intermittent Baffle Contacts," Nucl. Eng. Des., vol. 36, pp. $81-90,1976$.

9. R. J. Rogers and R. J. Plck, "Factors Assoclated with Support Plate Forces Due to Heat Exchanger Tube Vibration Contact," Nucl. Eng. Des., Vol. 44, pp. 247-253, 1977.

10. F. Axisa, A. Desseaux, and R. J. Gtlbert, "Experimental Study of Tube/Support Impact Forces in Multi-span PWR Steam Generator Tubes," ASME Sympostum on Flow-Induced Vibrations, Vo1. 3, pp. 139-148, 1984.

11. T. M. Frick, T. E. Sobek, and J. R. Reavis, "Overview on the Development and Implementation of Methodologies to Compute Vibration and Wear of Steam Generator Tubes," ASME Symposium on Flow-Induced Vibrations, Vol. 3, pp. 149-161, 1984.

12. "Standards of Tubular Exchanger Manufacturers Associates," Sixth Edition, 1978.

13. M. W. Wambsganss, H. Halle, and W. P. Lawrence, "Tube Vibration in Industrial Stze Test Heat Exchanger $\left(30^{\circ}\right.$ Triangular Layout - Six Crosspass Configuration), ANL Technical Memorandum, ANL-CT-81-42, 1981. 
14. H. Halle, Components Technology Division, Argonne National Laboratory, Private Communication, 1984.

15. R. B. Waterhouse, "Eretting 1n Hostile Environments," Wear, Vol. 34, pp. 301-309, 1975.

16. J. A. Jendrzejczyk, "Dynamic Characteristics of Heat Exchanger Tubes Vibrating In a Tube Support Plate Inactive Mode," ANL-84-39, 1984.

17. R. B. Waterhouse, "Fretting Corrosion," Pergamon Press, Oxford, 1972.

18. P. L. Hurricks, "The Mechanism of Fretting - A Review," Wear, Vol. 15, pp. 389-409, 1970.

19. Nam P. Suh, "The Delamination Theory of Wear," Wear, Vo1. 25, pp. $111-124,1973$.

20. Herbert H. Uhlig, "Mechanism of Fretting Corrosion," Trans. ASME, J. of Applied Mechan1cs, Vol. 21, pp. 401-407, 1954. 
Distribution for ANL-85-38

\section{Internal:}

J. J. Roberts

R. S. Zeno

M. W. Wambsganss (50)

R. E. Holtz

M. J. Bernard

E. F. Bielick

S. S. Chen

H. H. Chung

H. M. Chung
H. Halle

J. A. Jendrzejczyk

T. M. Mulcahy

Y. W. Shin

S. K. Zussman ANL Patent Dept. ANL Contract File ANL L1braries TIS Files (6)

\section{Externa1:}

DOE-TIC (30)

Manager, Chicago Operations office, DOE

Director, Technology Management D1v., DOE-CH

D. L. Bray, DOE-CH

Components Technology Division Review Committee:

P. Alexander, Flopetrol Johnston Schlumberger, Houston, TX

D. J. Anthony, General Electric Co., San Jose, CA

A. Blshop, U. Pfttsburgh

B. A. Boley, Northwestern U.

F. W. Buckman, Delian Corporation, Monroeville, PA

R. Cohen, Purdue U.

J. Weisman, U. Cincinnat 1 